DOI: http://dx.doi.org/10.22198/rys.2018.71.a385

Artículos

\title{
El sector citrícola de Nuevo León: caracterización del sistema agroalimentario como plataforma de integración del productor con la agroindustria
}

The citrus sector of Nuevo León: characterization of the agri-food system as a platform for integration of the producer with agro-industry

\author{
Gerardo Macario Pantoja Zavala* \\ Felipe Flores Vichi**
}

Resumen: el objetivo del estudio es identificar a los productores y comercializadores del sistema citrícola de Nuevo León, para integrarlos al sector agroindustrial a partir de los procesos del enfoque metodológico de los sistemas agroalimentarios localizados. Con la teoría de los distritos agroindustriales y un análisis previo de la región con perspectiva histórica, geográfica, productiva y de relación entre los actores,

\footnotetext{
* Doctor en ciencias sociales con orientación en desarrollo sustentable por el Instituto de Investigaciones Sociales de la Universidad Autónoma de Nuevo León (UANL). Profesor de tiempo completo y Secretario académico en la Preparatoria Núm. 25 "Dr. Eduardo Aguirre Pequeño". Dirección: Francisco Villa y Morelos s/n, colonia Ex Hacienda El Canadá, C. P. 66050. General Escobedo, Nuevo León, México. Teléfonos: (81) 8397 3006; 80584324 y 8058 4483, extensión 117. Correos electrónicos: gerardo.pantoja.uanl@hotmail.com / gerardo.pantojaz@uanl. mx / gerardo.pantoja.uanl@gmail.com

** Catedrático del Consejo Nacional de Ciencia y Tecnología. Instituto Politécnico NacionalCentro Interdisciplinario de Investigación para el Desarrollo Integral Regional, unidad Durango. Sigma \#1 19, fraccionamiento 20 de Noviembre II, C.P. 34220. Durango, Durango, México. Correo electrónico: flovich@gmail.com

Autor para correspondencia: Gerardo Macario Pantoja Zavala.
} 
de acuerdo con el esquema productivo, se podrá medir la articulación de éstos en virtud de sus atributos y diferencias, lo que creará condiciones de competitividad en el sector citrícola, y generará unidades empresariales basadas en la equidad y el manejo pertinente de los recursos naturales encaminados a las generaciones venideras. Los estudios sobre agricultura regional contribuyen a establecer la seguridad alimentaria, la estabilidad laboral y el desarrollo territorial y ambiental, según la premisa del desarrollo sustentable.

Palabras clave: territorio; desarrollo; sistemas productivos locales; cluster; asociatividad; acción colectiva.

Abstract: the aim of the study is to identify the producers and marketers in Nuevo Leon's citrus system in order to integrate them into the agro-industrial sector on the basis of the processes of the methodological approach to the localized agri-food systems. Using the agro-industrial districts theory and through a prior analysis of the region from a historical, geographical, productive perspective and taking into consideration the relationship among actors, according to the productive scheme, it will be possible to measure the interconnection among these by virtue of their attributes and differences. This will create competitive conditions in the citrus sector and generate business units based on equity and the appropriate management of natural resources destined to future generations. Studies on regional agriculture contribute to food security, job stability and territorial and environmental development, according to the sustainable development premise.

Key words: territory; development; local productive systems; cluster; associativity; collective action. 


\section{Introducción}

A lo largo de la historia, las distintas épocas han marcado diferencias entre sí, por ejemplo la revolución industrial provocó cambios y trasformaciones económicas, políticas y sociales que arrastraron al mundo a vivir el progreso que hoy es muy cuestionado, debido a sus consecuencias en todos los ámbitos de la sociedad. Con la revolución industrial se pensó que el mundo dejaría de padecer problemas apremiantes como la alimentación, que con las grandes innovaciones e invenciones se gestarían fuentes de empleo, como respuesta a los despidos masivos de trabajadores sustituidos por las máquinas productivas. Resultó fácil creer que el progreso estaba próximo, porque hubo grandes mejorías, pero existen sectores como el agrícola que no se integran a una dinámica de desarrollo, sino que al contrario se ha contraído y el avance regional está estancado, lo que repercute en la calidad de vida de la población.

El crecimiento en el sector agrícola ha sido desigual y asimétrico, por lo que la conjunción entre sus actores no es óptima y la ayuda de los programas es parcial debido, principalmente, a la falta de proyectos con una detección seria de necesidades y de decisiones justas en función del tamaño de las tierras, "ya que las necesidades son calculadas con base a la producción de fruta por árbol; para irrigación es probable se requieran esquemas de alta frecuencia en su aplicación" (Rocha 2009, 39). Algunos proyectos gubernamentales se trazan para ayudar a la mecanización de las labores, y la entrega de los apoyos está en función de análisis homogéneos que no hacen diferencias entre las particularidades de cada territorio.

De esta manera, las regiones son la fuente verídica de la situación imperante en el mundo, y a través de su caracterización se pueden guiar o establecer estrategias que en virtud del desarrollo agrícola se traducirían en equipamiento, producción, competitividad y fuentes de trabajo. La esperanza de cambio radica en que el desarrollo económico de un país o región se oriente a elevar el bienestar de la población, y que sea sustentable con respeto pleno al medio ambiente y con acceso a los recursos naturales (Bueno 2003, 5). Por eso urge una estrategia fundamentada en los ámbitos económico, político y cultural debido a que hay problemas que inciden indirectamente sobre todos los aspectos sociales. 
Por lo tanto, la herencia de la revolución industrial es un antecedente central de la causa de algunos problemas que se han agudizado en la actualidad. La aparición de las tecnologías acentuó los grandes cambios y las trasformaciones económicas, pero también su influencia se refleja en la desigualdad y la mala distribución, la diferenciación entre regiones es cada vez mayor. Antes se apostaba por permitir que ciertos grupos se establecieran en territorios para generar fuentes de empleo y mejorar las condiciones, con la máxima de "mejorar la calidad de vida de las personas" (Sachs 1996, 44), que por lo común se emplea para definir el desarrollo, y era lo que se esperaba en las regiones, pero con el proceso de industrialización aparecieron grandes empresas que buscaban materias primas y recursos naturales con el argumento de generar crecimiento, y lo único que se logró fue trasformar a las regiones en meras referencias de ubicaciones geográficas de explotación económica (Sachs 2002, 26). Se generó empobrecimiento campesino, aunque en algunos lugares existen excedentes de productos que se venden a precios bajos, en otros causan interferencia con la producción local y la dejan desprotegida ante la incapacidad de acomodar su mercancía en el mercado (Mazoyer 2001, 4-10). Aquí se hace referencia a la citricultura como fuente alimenticia y generadora de empleos e ingresos, demandante de materias e insumos para su desarrollo, y se relaciona con la agroindustria mediante la trasformación de productos destinados al mercado de bienes.

\section{Sistema Agroalimentario Localizado}

Lo más importante por resaltar en esta temática es una triangulación muy marcada entre la economía, el espacio y el territorio habitable, esta perspectiva la utiliza Caldentey $(1998,21)$, quien señala que dicha triangulación destaca la importancia del espacio que inicia en la teoría de la localización de Von Thunen (1826), rama de la teoría económica caracterizada por la distribución de cultivos alrededor de una ciudad aislada.

También se agrega la importancia del trasporte como uno de los costos de producción determinante para la localización de la actividad económica. En el estudio se resalta que el territorio no es sólo el 
espacio físico, sino que incluye aspectos humanos y organizacionales para las relaciones económicas: los empleados, su colectividad, conducta, comportamiento, pensamiento y valores, que son parte de la teoría de la economía institucionalista representada por Coase, North y Williamson. Además de la definición de territorio, Caldentey alude a que el término se deriva de "producto de la tierra" $(1998,22)$, entendido como típico o producto tradicional que se puede definir como el que está ligado a un territorio y culturalmente a costumbres o modos, con un mínimo de permanencia en el tiempo y debiendo poseer características cualitativas y particulares que lo diferencien de otros.

Según Becattini, en la hortofruticultura aparecen rasgos de los distritos industriales, que se pueden aplicar al caso citrícola; los importantes son la existencia de una actividad económica dominante, un sistema de producción, las compañías que suministren inputs, el dominio de pequeñas y medianas empresas y también de las especializadas en una fase, las relaciones entre las firmas, la identificación entre empresas y personas y las instituciones con sistemas de valores y reglas. Con esto se destacan algunos elementos característicos de un enfoque que mantiene al territorio como núcleo de engranaje de una actividad económica con rasgos propios, costumbres y tradiciones contenidos en un área determinada geográficamente, la referencia directa es el Sistema Agroalimentario Localizado (SIAL), el cual resalta la importancia en la espacialidad y la temporalidad como elementos base para las trasformaciones socioeconómicas de los territorios. Las perspectivas teóricas que las originaron parten de los distritos industriales de Marshall, que destacan la importancia de la proximidad entre industrias, en específico se habla de una atmósfera industrial caracterizada por la división social del trabajo, con proveedores especializados, información acerca de los mercados y del saber hacer, además del desarrollo de un mercado laboral, que dará vida a los sistemas productivos locales. Un antecedente y sustento teórico que lo condicionó fueron los clusters, cuya máxima representación es el diamante de Michael Porter, quien se refería a grupos de empresas de un mismo sector, relacionadas y articuladas entre sí con eslabones de actores (Poméon 2011, 10-12). Un elemento más que se agrega a la fundamentación y al trayecto del SIAL son los sistemas productivos 
locales que se distinguen por lo pequeño, lo cercano y lo intenso, a esto se le conoce como la primera aproximación u oleada del SIAL (Boucher 2012, 19). Esto último construye el concepto de territorio con aspectos que lo hacen único como un espacio construido histórica, social y económicamente, marcado en términos culturales, y regulado por una institución (Muchnik 1998). Paul Krugman considera los conceptos de espacio y tiempo como el análisis de la actividad económica en la relación entre ellos para propiciar el desarrollo de una región (Poméon 2011, 12). Entonces, el vínculo economía y espacio trasformará al territorio en un espacio vivo (Poméon 2011, 13) resultado de una construcción social. El territorio se definirá entonces como un espacio de interacción dinámico, estructurado por proximidades, en el que se intercambian y se coordinan los actores, y forma un sistema que incluye varias esferas productivas, institucionales y organizacionales (Poméon 2011, 13).

El enfoque del SIAL surgió a finales de la década de 1990, por iniciativa de un grupo de investigadores de instituciones francesas como el CIRAD $^{1}$ y el INRA ${ }^{2}$ que se interesaron por las pequeñas empresas agroalimentarias en los países en desarrollo; su intención era analizar el papel de ellas en el desempeño de los sectores agrícolas y agroalimentarios, en la asimilación del territorio a una organización productiva (Poméon 2011, 5). La importancia del SIAL en los estudios del sector agrícola se debe a los trabajos conducidos por el CIRAD sobre pequeñas y medianas empresas agroalimentarias en África y agroindustrias rurales en América, se centraban en la problemática de la alimentación de poblaciones urbanas y la valorización de los recursos locales, para generar valor agregado a la agricultura familiar por medio del procesamiento de sus productos; refirieron la existencia de concentraciones locales de agroindustrias especializadas, las cuales movilizaban los recursos locales (Poméon 2011, 14). Lo anterior lleva a caracterizar la segunda fase u oleada del SIAL, identificada como la activación de los recursos, es decir, la movilización de éstos de manera colectiva a fin de mejorar la competitividad de las agroindustrias,

Centre de Coopération Internationale en Recherche Agronomique pour le Développement. Institut National de la Recherche Agronomique. 
es la capacidad de organizarse en torno a los recursos y combinarlos (Boucher 2012, 23-27).

A partir de aquí, el concepto definitivo tomó forma hasta que se consideró como un organismo de producción y servicios asociada a un territorio específico por su funcionamiento y características definitivas (Poméon 2011, 15), entre ellas la importancia de las redes como el aspecto sociocultural, que considera al territorio como parte integral del sistema productivo, que se distingue como un enlace fuerte con el medio geográfico y sus recursos naturales, presenta multiplicidad de saberes, el consumo de alimentos implica valores y atributos particulares, vinculados a aspectos físico-materiales y simbólicos identitarios: saber-identificar y saber-apreciar, hasta caracterizar a las zonas rurales por usos y costumbres (Poméon 2011, 18). La última actualización del SIAL implica la multifuncionalidad, la cual consiste en que la actividad agropecuaria conduce a la elaboración de productos alimentarios de calidad, a la que se suma la integración del turismo rural y ecoturismo, una canasta de bienes y de servicios, entre ellos los ambientales (Murillo 2012, 121-138).

La utilización de dos aspectos que fortalecerían el trabajo del SIAL, al reducir el estudio a cuestiones un tanto específicas de la producción y de sus actores en el territorio serían: a) la aplicación del método de análisis de redes, el cual se refiere a las relaciones sociales, técnicas y comerciales de la actividad agrícola o subsectores de ella y b) el recurso del análisis de cadena, a fin de valorar la interacción económica entre actores de diversos eslabones y estrategias de competitividad que desarrollan las agroindustrias (Grass 2012, 14-15). Estos aspectos cerrarían el círculo en el estudio de las relaciones entre actores, sus estrategias y alternativas que surgieran en la actividad económica y que son clave para el desarrollo de una región y su población. Muchnik y Sautier analizan a los SIAL como unidades agrícolas, empresas agroalimentarias y comerciales, las cuales tienden a mantenerse unidas a través de sus características y su funcionamiento en un espacio (Poméon 2011, 15), en el que hay dilemas y problemáticas que enfrenta el mismo círculo de relaciones mediante habilidades en común. En estas fases se destacan las variables materiales e inmateriales del territorio, y cómo influyen en la producción y el consumo de alimentos; las primeras se refieren a los recursos naturales y las 
segundas a las costumbres y las tradiciones que posibilitan el surgimiento del producto y su procesamiento (Grass 2012, 22).

La etapa anterior permite la activación de recursos debido a las variables materiales, aunque en esta fase Grass $(2012,24)$ se refiere a la movilización de los recursos (endógenos y exógenos) de manera organizada, lo señala de forma colectiva para mejorar la competitividad. La manera de realizarla es adentrándose en la teoría de la acción colectiva, la que retoma dos maneras desgajadas: la acción colectiva estructural, los aspectos organizativos en la región a través de asociaciones, cooperativas u otro tipo de uniones; mientras la acción colectiva funcional se refiere a que en unión se puede producir una marca colectiva que haga referencia a una identidad geográfica. La misma unidad social y económica generará la fase de multifuncionalidad, donde las redes sociales y organismos se fortalezcan institucionalizándose, a fin de potenciar la acción colectiva y facilitar la activación de recursos, la calificación y la certificación de productos.

La descripción y caracterización del SIAL contribuye a manejar una alternativa seria de apoyo para solucionar problemas en la zona citrícola de Nuevo León, pues los cítricos se pueden considerar productos, como los categorizan en la región argentina, surgen de un saber y conocimiento local, son elementos dinamizadores de tierras, y fruto de la historia y la dinámica de territorios particulares (Velarde 2012, 141). La acción colectiva y los recursos específicos están en la base de la diferenciación del territorio, asociada a la capacidad de los actores para la elaboración y la difusión de innovaciones que son componentes importantes de la competitividad de una empresa. La acción colectiva estructural con la creación de un grupo formal crea un marco para encuentros en intercambios favorables a los aprendizajes colectivos, y la acción colectiva funcional remite a la construcción de un recurso territorializado en relación con la calidad de un bien (Poméon 2011, 50).

Los procesos de innovación remiten a dinámicas de aprendizaje colectivo, resultan de las modalidades de coordinación entre agentes diferentes, en un espacio de proximidad dado, y se insertan a menudo en redes sociales (Poméon 2011, 53). La incorporación del SIAL a la región citrícola es pertinente al contar con la identificación de los componentes sistémicos del procedimiento, los actores, las acciones, 
los procesos y los efectos que interactúan entre sí. La visión sistémica implica diferenciar el interior del sistema de lo que constituye su contexto. Las características de un sistema, según Filippa, son la unicidad del conjunto (forma una unidad), la estructuración y el mantenimiento de objetivos comunes, compartidos por sus componentes, y los rasgos propios que los diferencian (Poméon 2011, 28), estos objetivos son el mosaico de pensamientos, problemas y alternativas que mostrarán los actores.

\section{Metodología}

La elaboración de este estudio se organizó en tres esquemas, el primero consistió en una revisión documental para el abordaje histórico y de ubicación geográfica, lo cual permitió conocer los factores principales que originaron la formación de la zona citrícola de Nuevo León. Se partió del origen de la citricultura en el estado con los textos de Olvera Sandoval (1987), y con la evolución económica regional de Sánchez (1990); para caracterizar la región se consultó a Merla Rodríguez (1990), y para la ubicación histórica de la transición estructural agraria de esta actividad económica se analizó a Fujigaki (2000). Asimismo, se examinaron documentos de Sieglin (1995; 1987), quien se refiere a la trasformación y al desarrollo capitalista regional. También se consultó a Vázquez y González (1987), quienes aluden a un personaje capitalista importante en el desarrollo local. La revisión cierra con la referencia a la experiencia de la zona citrícola de Nuevo León en el mercado agrícola nacional e internacional de Luna Moliner (2014).

En el segundo esquema se estructuró la utilización de herramientas como fuentes directas y originales para obtener información. Aquí se utilizó la encuesta aplicada a 14 casos identificados como comercializadores y distribuidores de cítricos, dicho material surgió de la guía metodológica de los SIAL con la finalidad de elaborar el esquema completo del funcionamiento de la actividad citrícola de Nuevo León, y especificar el objetivo del instrumento que alude a obtener la información de los comercios en la central de abasto del estado, para 
conocer las relaciones desde los productores hasta los agroindustriales. La elaboración de dicho instrumento consistió en cuatro núcleos que configuran los datos que establecerán las relaciones entre actores. El primero, llamado información general, se integra con el perfil del negocio de abasto, su antigüedad y el tipo de productos que distribuye o comercializa. El segundo consiste en la relación con los proveedores, mantiene el origen de los productos y el tipo de relación entre ellos, aspecto esencial que lleva a conocer los aspectos siguientes: a) las relaciones hacia atrás (internas); b) la clasificación de los cítricos como fase previa a la calidad del producto; c) la existencia de alguna relación o sinergia entre actores que condicione el establecimiento de una marca colectiva hacia donde se dirige el producto, esto sirve para verificar las relaciones hacia adelante (externas); d) el periodo de pago; e) el financiamiento por la mercancía, el costo del trasporte y el traslado; f) la capacidad de almacenamiento, y g) la cantidad de mermas antes de la comercialización. El tercer núcleo, que es la relación con los clientes, se caracteriza por saber cuántos configuran la comercialización del producto, la calidad que solicitan para fortalecer sus relaciones, la presentación para comercializar el producto, la forma de pago, donde incide drásticamente el clima y la permanencia promedio del producto en bodegas, situación que genera costos de compraventa. El cuarto núcleo corresponde a la información original, se refiere a las ventas de cítricos en los últimos tres años, la utilidad de bodegas para almacenamiento y la incursión de cítricos sin semilla. La encuesta permitió obtener la materia prima del estudio, además fue el termómetro de las situaciones regionales y nacionales en la temática.

El motivo para dirigir e implementar la encuesta hacia la comercialización es que este proceso es el intermedio entre la obtención, la industrialización y el procesamiento del producto para que llegue al consumidor final. Asimismo, dicho análisis identificó, a través de un esquema, el modo lineal vertical de los actores involucrados cuya

estrategia de complementación se basa en el deseo de contar dos imágenes distintas de la realidad social en la que está interesado el investigador. Dado que cada método ofrece, por su propia naturaleza, una imagen distinta, dado que cada uno revela aspectos 
diferentes, podemos ampliar nuestro conocimiento de la realidad social si realizamos una investigación con dos estructuras metodológicas paralelas (Bericat 1999, 106).

El tercer esquema se refiere a la entrevista, "considerada como una técnica orientada a establecer contacto directo con las personas que se consideren fuentes de información [...] y ubicar a los actores del estudio dentro de un perfil contextual” (Bernal 2006, 177). Este instrumento posee un guión específico, nutrido de los SIAL, se estructura con el perfil socioeconómico, y contiene aspectos generales acerca de la producción y el tipo de tenencia de la tierra. Después se analizan los aspectos técnicos del cultivo, asimismo, contiene cuestiones que involucran al recurso hídrico: sistema o esquema de riegos. También analiza costos de trasportación junto al destino del producto: empaque, industria, comercio local, tianguis regional y otros actores que participan como acaparadores o intermediarios. El criterio de selección de este instrumento utilizó 156 informantes, productores de cítricos de los municipios de Cadereyta Jiménez (28), General Terán (30), Linares (28), Allende (17), Montemorelos (31) y Hualahuises (22). Los instrumentos fueron útiles para configurar una matriz de fortalezas, oportunidades, debilidades y amenazas obtenidas de las visiones de los actores, los entrevistados y los encuestados. La descripción de las características de la producción citrícola será un preámbulo de identificación de los trabajos desarrollados, y permitirá conocer las formas de organización de productores y empresas.

\section{Descripción histórica de la citricultura de Nuevo León}

La citricultura comenzó a finales del siglo XIX cuando las actividades principales de la región eran la siembra de maíz y el cultivo de caña de azúcar (Sánchez 1990, 11-29); tuvo tres momentos que la solidificaron, analizados en una estructura establecida por Gutelman, se construye el encuadramiento agrario a través de las etapas históricas de México (Fujigaki 2000, 14). Sin embargo, de este esquema, característico de la comunidad prehispánica, la hacienda, el rancho, la plantación, el ejido parcelado, el ejido colectivo, la pequeña propiedad, la 
empresa agrícola y el latifundio, se pueden distinguir tres momentos en Nuevo León. El primero, de 1820 a fines de 1890, cuyo rasgo fue la falta de tierra para la agricultura, pues las haciendas dominaban el territorio; el segundo, de los primeros 40 años del siglo XX, con el reparto agrario y la constitución de los ejidos parcelados o colectivos, el cual significó el triunfo de los ideales de la revolución mexicana, aunque con la ausencia de las herramientas para trabajar la tierra, y el tercero, las sequías de los años ochenta, la introducción previa de los cítricos por Robertson en la última década del siglo XIX, que se tradujo en el establecimiento de la empresa agrícola como sociedades mercantiles o comerciales, al destacar que la formación de productores citrícolas es el resultado de la distribución de la tierra, se inició como un negocio pequeño que fue acumulando ganancias como capital que incursionó en la industria con el jugo y el gajo de la naranja.

Durante el porfiriato incursionaron grandes inversionistas que propiciaron una coyuntura socioeconómica en Nuevo León. En 1887, Joseph A. Robertson se involucró en el ámbito agrario ante la fertilidad de bosques y sembradíos, donde vislumbró invertir en un producto de fácil acomodo en el mercado estadounidense, pues se tenía acceso y contactos con el extranjero, además ya había adquirido muchas hectáreas de terreno cultivable (Olvera 1987, 151-176). Siete años más tarde se obtuvieron cosechas abundantes de naranja, lo que generó el crecimiento de esta actividad a través de la apertura de mercado de Estados Unidos que consiguieron los productores pioneros, situación que motivó a otros para incursionar en el negocio. "En sus viajes de inspección como gerente del Ferrocarril al Golfo, Robertson observó las tierras fértiles de Montemorelos y determinó la factibilidad del cultivo de naranja en esta zona tradicionalmente dedicada a la siembra de maíz y caña de azúcar" (Vázquez 1987, 187). Con la citricultura, "al finalizar el siglo se emprendió una paulatina modificación de la estructura productiva” (Sieglin 1995, 67).

Sin embargo, el proceso revolucionario mexicano trastocó la economía del país, y constituyó el primer gran desafío que enfrentó la naciente actividad citrícola. No obstante, al pasar esta etapa, "la crisis económica de fines de los veinte, cuando surgió una fuerte orientación a expandir el cultivo del cítrico y a la exportación de la naranja (ante las perspectivas de ganancias más altas en comparación con los 
productos básicos). Se sentaron así las bases para un desarrollo capitalista regional sustentado con nitidez en la producción de cítricos en gran escala [...]” (Sieglin 1987, 234).

Durante la década de 1930 se detectó que la actividad citrícola necesitaba evolucionar y "hasta después de la primera mitad de los treinta los citricultores todavía no empleaban plantas empacadoras. La naranja llegaba a los mercados sin ser seleccionada por tamaños, ni aseada ni envuelta" (Sieglin 1987, 218). Fue necesaria la aplicación paulatina de innovaciones para la selección del producto, que fue uno de los objetivos a corto plazo, debido a que "comparado con Estados Unidos, España y Palestina, los citricultores mexicanos casi no tenían posibilidad de competir en forma ventajosa en los mercados internacionales debido al atraso de la producción en el país" (Sieglin 1987, 218). Ante estos inconvenientes, “el Estado asumió un papel importante impulsando la expansión del cultivo [...] y desarrollando infraestructura para facilitar la exportación y proliferación de centros de consumo" (Sieglin 1987, 219). Con estos proyectos, a partir de los treinta "la exportación de naranja en cualquiera de sus formas, se mantuvo con valores menores a las $5 \mathrm{Gg}$ (miles de toneladas). Posteriormente (1950-77), la exportación de esta fruta tuvo un incremento significativo hasta llegar a los 106 Gg en 1977" (Vázquez 1990, 174).

A pesar de que existía una empresa de empaque que se había "fundado a finales de los 30 en Montemorelos. En el transcurso de los 40 se constituyeron tres más. Sin embargo, sus capacidades de empaque fueron mínimas" (Sieglin 1995, 125). En los primeros años de la década de 1970 se organizó la Unión Nacional de Citricultores (Sieglin 1995) para generar planes de estabilización de la actividad, por lo cual "se enfocaron en la industrialización de la fruta (jugos naturales y concentrados, gajos enlatados), lo que motivó a establecer una agroindustria en la región" (Sieglin 1995, 125), para que se fuera conformando la zona citrícola de Nuevo León. Esta perspectiva histórica explica y permite concluir que: "En la actualidad la región citrícola cuenta con más de un siglo de experiencia como productora de cítricos para el mercado nacional e internacional, al cual se orientan formas tradicionales de producción y comercialización” (Luna 2014, 41). 


\section{El sector citrícola de México}

Según el sitio Mexican Business:

México es el quinto productor a nivel mundial de cítricos, con 7.1 millones de toneladas anuales, en su mayoría naranjas y limones, y en menor cantidad mandarina, tangerina, toronja, lima y limón real, de acuerdo con el Grupo Consultor Mercados Agrícolas (GCMA). Los principales productores de cítricos en el mundo son China (24 millones de toneladas anuales), Brasil (21 millones), Estados Unidos (10 millones) e India (10 millones) (Cano 2013).

En 2012, el informe "México, entre los líderes de cítricos a nivel mundial” destacó que el país aportaba 4.6 por ciento de cítricos en el mundo, sólo por debajo de China (21), Brasil (18), Estados Unidos (8) e India (6). Las principales entidades productoras de cítricos son Veracruz, con 55 por ciento; San Luis Potosí y Tamaulipas aportan 22 y entre Puebla y Nuevo León se distribuye 23 por ciento (Secretaría de Agricultura, Ganadería, Desarrollo Rural y Pesca, SAGARPA 2012). El buen posicionamiento permite evidenciar la importancia de esta actividad, pero también se sabe que ha habido fallas en la producción debido a los fenómenos climáticos y a los costos elevados. En la Figura 1 se muestra el retroceso en la producción de la mandarina y la naranja, mientras que se visualiza un crecimiento en la toronja.

Figura 1. Producción citrícola nacional en toneladas

\begin{tabular}{|c|c|c|c|c|c|}
\hline Producto & 2008 & 2009 & 2010 & 2011 & \multicolumn{1}{c|}{2012} \\
\hline Naranja & 352061.01 & 296976.71 & 236493.46 & 271954.56 & 204749.85 \\
\hline Mandarina & 46123.50 & 35891.50 & 32110.00 & 27868.50 & 34229.63 \\
\hline Toronja & 20633.75 & 17734.20 & 20069.10 & 22443.00 & 26425.50 \\
\hline
\end{tabular}

Fuente: elaboración propia, con datos de la Oficina Estatal de Información para el Desarrollo Rural Sustentable, OEIDRUS (2011); Sistema de Información Agroalimentaria y Pesquera (SIAP 2013). 
Figura 2. Volumen y valor porcentual de la producción agrícola en Nuevo León

\begin{tabular}{|c|c|c|c|}
\hline Cultivo & Lugar nacional & \% volumen & \% valor \\
\hline Mandarina & 3 & 1 & 1 \\
\hline Toronja & 4 & 1 & 1 \\
\hline Naranja & 5 & 7 & 8 \\
\hline
\end{tabular}

Fuente: elaboración propia, con datos de la OEIDRUS (2011), con información del SIAPSAGARPA (2012).

Como se muestra en la Figura 2, la posición de Nuevo León en el volumen y valor agrícola acentúa aún más la importancia de la actividad en la región.

\section{Panorama de la citricultura en Nuevo León}

Nuevo León cuenta con 392415 hectáreas destinadas a la agricultura; representan 6 por ciento de la superficie total de la entidad, donde 67 por ciento es de temporal y 33 de riego. En los municipios del centro y sur del estado se concentra 82 por ciento del área agrícola, donde se genera casi 1.5 por ciento de los productos cosechados en México cuyo valor es de 3032 millones de pesos, 46 por ciento se genera en municipios del sur, 32 en la zona centro-citrícola y 22 en la norte. En Montemorelos, General Terán y Cadereyta Jiménez se cosecha naranja, mandarina y toronja (355 mil toneladas al año), que representan 80 por ciento de los cultivos del estado (SIAP-SAGARPA 2012).

Para 2012, de acuerdo con el SIAP-SAGARPA, los cultivos principales en el estado fueron la mandarina, que ocupó el tercer lugar nacional, con 12 por ciento del volumen; la naranja se colocó en el cuarto sitio, con 6.7 por ciento, al igual que la toronja, con 5.6 por ciento de producción nacional (SIAP-SAGARPA 2012). Estos frutos se sembraron en una triangulación de espacio, territorio y actividad económica, donde los dos primeros factores son condicionantes para el desarrollo de la economía, sin dejar de lado que incluyen a la población, sus labores, el rol que desempeñan en su trabajo y el comportamiento dentro de las empresas, entre otros aspectos (Caldentey 1998). 


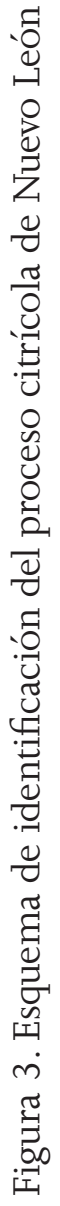

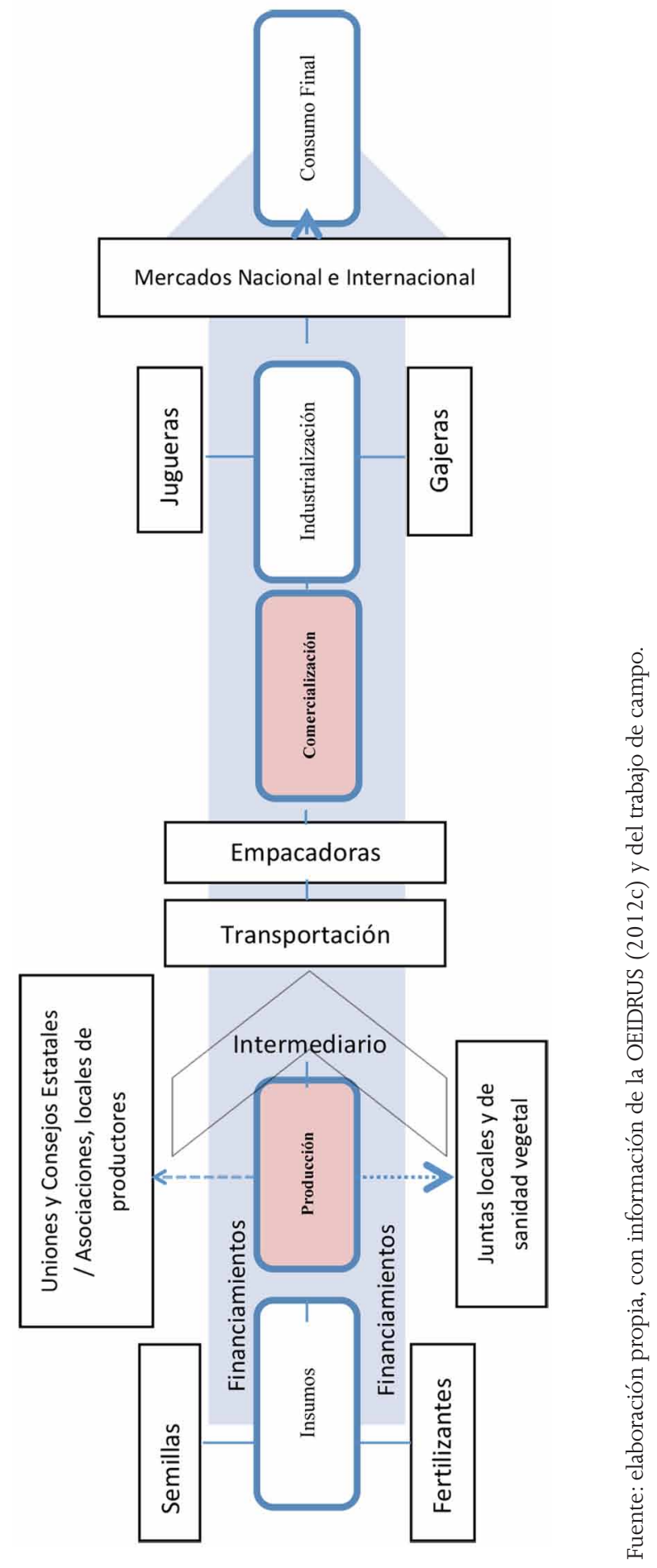




\section{Identificación del proceso citrícola de Nuevo León}

Los participantes en el proceso son los citricultores, los procesadores, los comercializadores y los medios de trasporte. La cadena productiva se conforma con proveedores de insumos y servicios, productores, empacadores, procesadores y comercializadores (OEIDRUS 2012). La operatividad del proceso agrícola comienza con los proveedores de agroquímicos y servicios de planta injertada para reconversión, los apoyos de la banca y de parafinancieras, los cuales se dirigen hacia los productores de los municipios de General Terán, Cadereyta Jiménez, Allende, Montemorelos, Linares y Hualahuises, donde se obtiene la producción de cítricos de Nuevo León para su comercialización, proceso en el que intervienen el trasporte, para trasladar los productos agrícolas a las empacadoras; las jugueras de la región y los mercados de abastos y supermercados, para el consumo final (OEIDRUS 2012). Según la descripción anterior, en el proceso de comercialización confluyen los productores con el sector agroindustrial y el consumidor final (véase Figura 3).

La revisión de las ubicaciones de producción y comercialización (véase Figura 3) son procesos importantes unidos a través de los puentes de intermediarios, trasportación y empaques, para que el producto se envíe directamente al procesamiento con sus mercados finales. La identificación permite señalar que los insumos como la semilla y los fertilizantes son parte de la materia prima para iniciar el proceso, pero también hay apoyos, a través de financiamiento, para proyectos cuyo objetivo es valorizar la cadena productiva, el manejo de riesgos y para la innovación tecnológica (Fideicomisos Instituidos en Relación con la Agricultura, FIRA 2016), dichos soportes son catalizadores, y serán los puentes donde se identifiquen elementos descriptivos para el accionar asociativo.

\section{Perspectiva regional de la citricultura en Nuevo León}

Nuevo León tiene la forma de un rombo irregular cuyo eje norte-sur es de 504 kilómetros y 310 en la parte más ancha (Merla 1990, 1314). La zona citrícola se localiza en la llanura costera del golfo, con 
las regiones norte y centro del estado, que es semiárida y plana. Los municipios que producen cítricos son Montemorelos, Cadereyta Jiménez, General Terán, Linares, Hualahuises, Allende y Rayones.

La descripción histórica y geográfica de Nuevo León define las tendencias productivas de cítricos en la zona, y el principal es la naranja, por lo que es la representante de los cítricos en el estado. Por tal motivo, según el SIAP, dicho fruto es uno de los más populares, y México es uno de los primeros productores mundiales. Su uso más frecuente es en jugo, aunque también se aprovecha para elaborar mermeladas, aceites y esencias (que se obtienen de la cáscara); aromatizantes y saborizantes. Además, es un ingrediente en diversos platillos de la cocina mexicana (SIAP-SAGARPA 2011).

El cultivo de los cítricos es muy importante en la región, por la gran derrama económica que deja, y por la mano de obra que necesita, un factor primordial para la población: la generación de empleos.

Figura 4. Tendencias de la producción anual en toneladas

\begin{tabular}{|c|c|c|c|c|c|c|c|c|}
\hline Año & 2005 & 2006 & 2007 & 2008 & 2009 & 2010 & 2011 & 2012 \\
\hline Toneladas & 290011 & 317422 & 323982 & 351280 & 296019 & 235202 & 270819 & 203804 \\
\hline
\end{tabular}

Fuente: elaboración con datos de la OEIDRUS (2013).

El descenso en la producción se debe a la baja precipitación y a las altas temperaturas que han repercutido en su rendimiento. En el año 2000 el rendimiento promedio fue de $8.3 \mathrm{t} / \mathrm{ha}$, después de que en 1982 fue de 14.7 t/ha, y de 15.7 t/ha, en 1997. La vulnerabilidad de la región citrícola por la falta de agua para riego se debe en gran medida al abatimiento de los mantos acuíferos y a los escurrimientos de la base del río Pilón. La década de 1990 se caracterizó por una sequía que marcó un cambio en el uso del agua hacia sistemas de riego tecnificados (Gaitán 2002, 69). 


\section{La superficie agrícola de los cítricos en Nuevo León}

La producción de los cítricos se divide en agricultura de riego y de temporal; la primera es la más importante para las funciones productivas. Los municipios de General Terán y Montemorelos aplican mayoritariamente técnicas de riego dependientes de la tecnología (véase Figura 5 y 6 ).

Figura 5. Hectáreas de riego y de temporal en el cultivo de cítricos en Nuevo León

\begin{tabular}{|c|c|c|r|r|c|}
\hline Municipio & Riego & \% & Temporal & \multicolumn{1}{c|}{$\%$} & Total de hectáreas \\
\hline Montemorelos & 7437 & 76.5 & 2284 & 23.5 & 9721 \\
\hline General Terán & 8651 & 93.0 & 648 & 7.0 & 9299 \\
\hline Cadereyta Jiménez & 4175 & 71.5 & 1668 & 28.5 & 5843 \\
\hline Linares & 2670 & 97.6 & 65 & 2.4 & 2735 \\
\hline Allende & 397 & 17.3 & 1904 & 82.7 & 2301 \\
\hline Hualahuises & 1871 & 93.9 & 121 & 6.1 & 1992 \\
\hline Total zona & 25201 & 79.0 & 6690 & 21.0 & 31891 \\
\hline
\end{tabular}

Fuente: elaboración con datos de la OEIDRUS (2011).

Figura 6. Distribución de la agricultura de riego y temporal por especie

\begin{tabular}{|c|c|c|c|r|c|r|}
\hline Especie & \multicolumn{1}{|c|}{ Riego } & \multicolumn{1}{c|}{$\%$} & Temporal & $\%$ & Total de hectáreas & \multicolumn{1}{c|}{$\%$} \\
\hline Naranja & 20390 & 77.0 & 6074 & 23.0 & 26464 & 83.0 \\
\hline Mandarina & 3131 & 87.3 & 454 & 12.7 & 112 & 11.2 \\
\hline Toronja & 1680 & 91.2 & 162 & 8.8 & 5.8 & 5.8 \\
\hline Total & 25201 & 79.0 & 6690 & 21.0 & 31891 & 100.0 \\
\hline
\end{tabular}

Fuente: elaboración con datos de la OEIDRUS (2011).

\section{La producción en el periodo 2006-2011}

La producción de cítricos en Nuevo León se ubica en la agricultura de riego, y los municipios de Montemorelos y General Terán contienen casi 60 por ciento, mientras que Linares, Hualahuises, Cadereyta Jiménez y Allende completan la superficie (Gaitán 2002, 70-78). 
Nuevo León se mantiene entre los principales estados productores de cítricos del país, con 7 por ciento; Puebla, con 6, y el líder es Veracruz, con 49; le siguen Tamaulipas, con 13, y San Luis Potosí, con 9 (Mexbest Safety and Quality Taste s/f). Como ya se mencionó, la mandarina, la papa, la naranja y la toronja son los productos regionales principales. Además, se cultiva manzana, nuez, pastos, trigo de grano y sorgo forrajero; aunque predominan los cítricos (véase Figura 7).

Figura 7. Dimensionas asociadas para lograr la satisfacción y lealtad del cliente mediante la mercadotecnia relacional

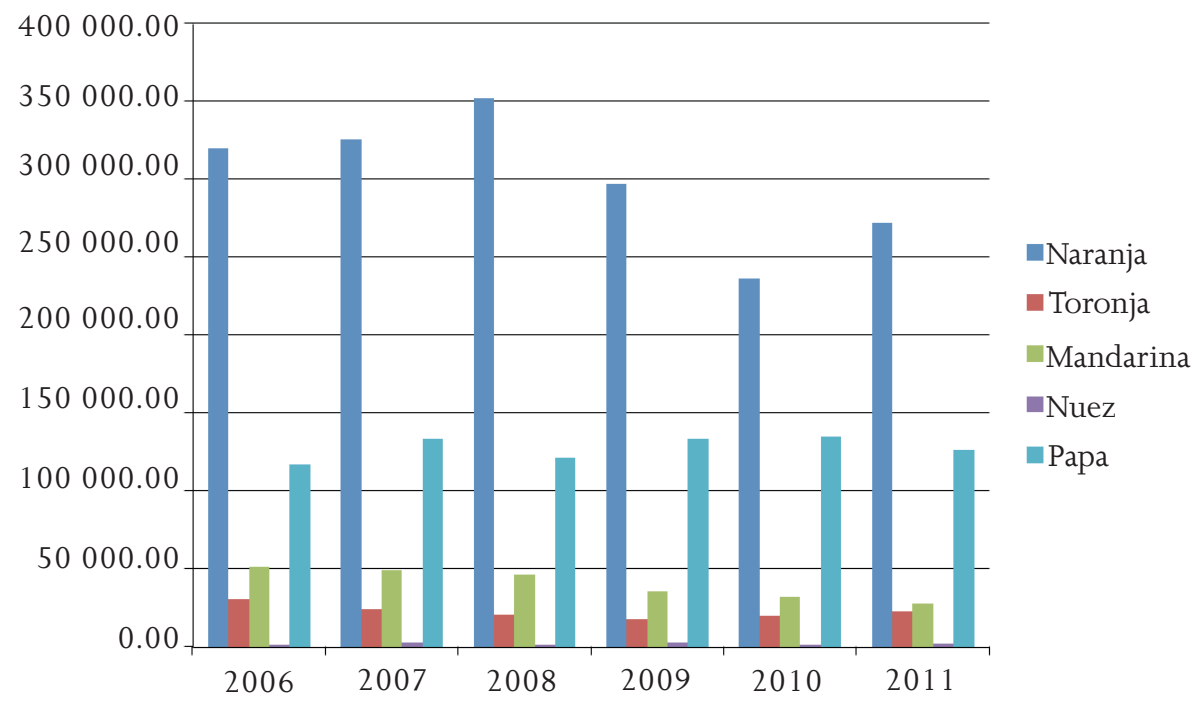

Fuente: elaborado con datos de la OEIDRUS Nuevo León (2012a).

A pesar de lo anterior, según el producto interno bruto (PIB) de Nuevo León, la actividad primaria es baja e irrelevante (véase Figura 8). Esto quizá obedezca a condiciones históricas de la región, pues las actividades industriales mantienen parte del control del desarrollo económico del país, junto al Distrito Federal y Guadalajara. Los datos obtenidos permitieron visualizar las tendencias y la importancia de la citricultura de Nuevo León. 
Figura 8. Aportación de Nuevo León al PIB

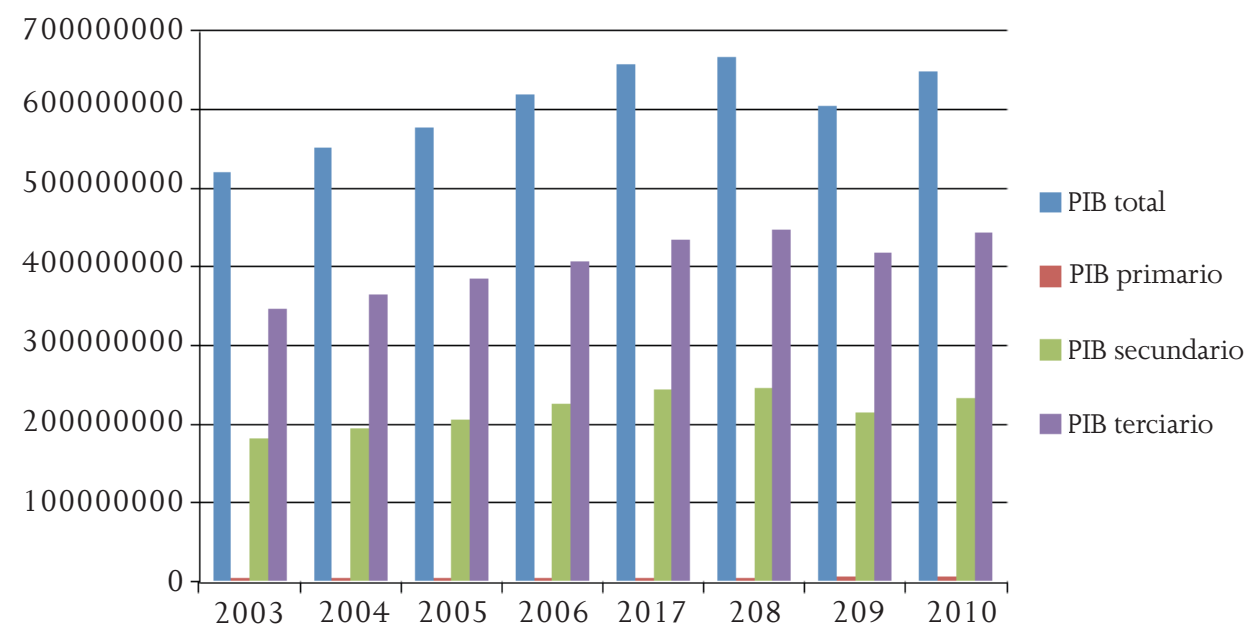

Fuente: elaborado con datos de la OEIDRUS Nuevo León (2011).

\section{Resultados}

Análisis de los productores de cítricos de Nuevo León

Esta sección aporta conocimiento acerca de las características con amplias ventajas de crecimiento y organización a partir de los primeros actores, quienes enfrentan la ardua tarea de colocar adecuadamente sus productos en el mercado ya sea de manera directa, de acuerdo con la oferta y demanda, o indirecta, a través de los intermediarios. El análisis aborda la producción y distribución, y destaca de forma cuantitativa el tipo de tenencia de la tierra, las formas de abastecimiento de agua, el sistema de riego y las relaciones comerciales. La estructuración del sector productivo depende de la producción y 
la comercialización posterior, y también del efecto hacia adelante, porque se refiere a los actores con que se relacionan para colocar el producto fuera de sus demarcaciones, y hacia atrás, porque identifica las necesidades y los obstáculos para obtener el producto. En cuatro municipios prevalece la pequeña propiedad en la tenencia de la tierra; en Cadereyta Jiménez predomina la ejidal, al igual que en Linares, con 57 por ciento, y otro 43 corresponde a la pequeña propiedad (véase Figura 9).

Figura 9. Tenencia de la tierra en los municipios citrícolas de Nuevo León

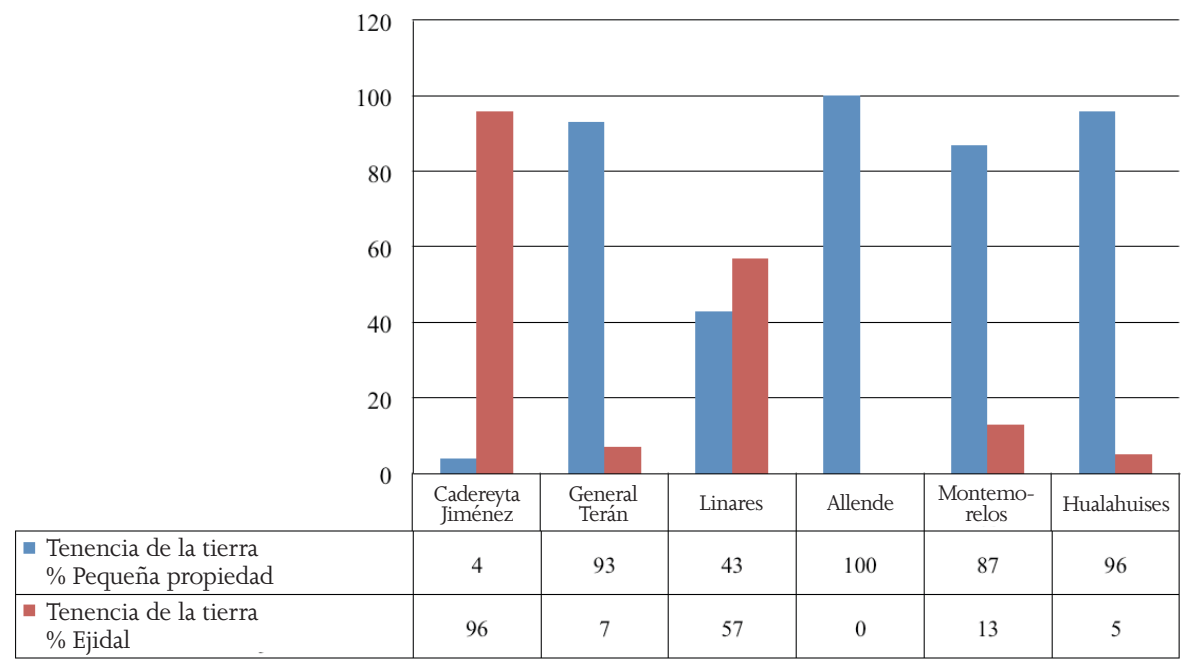

Fuente: elaboración propia, con datos del trabajo de campo.

En cuanto al sistema de riego, en Cadereyta Jiménez, General Terán y Linares predomina el de gravedad; en Allende y Montemorelos el sistema de temporal y en Hualahuises por microaspersión (véase Figura 10). 
Figura 10. Sistemas de riego por municipio

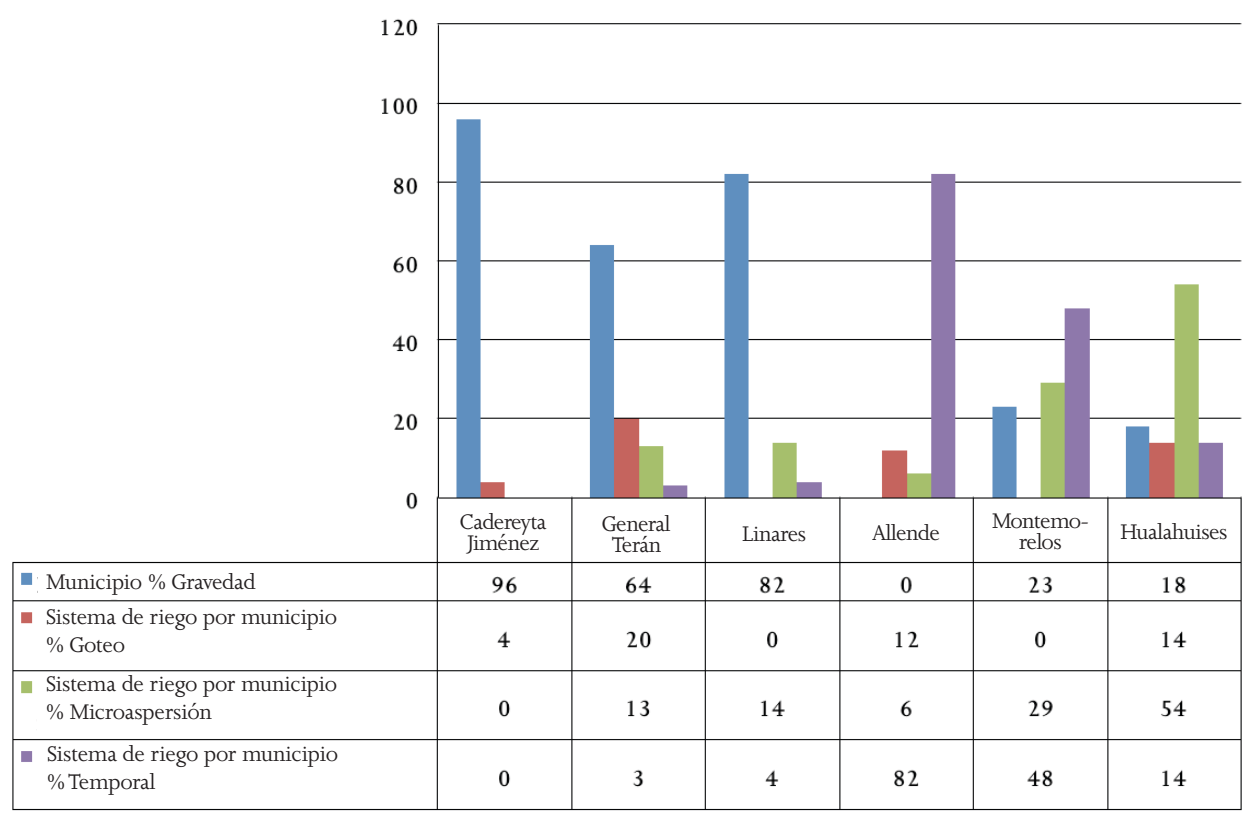

Fuente: elaboración propia, con datos del trabajo de campo.

Más de 80 por ciento del abastecimiento de agua en Allende, Montemorelos y Hualahuises es de pozo, y poco más de 37 en General Terán (véase Figura 11). 
Figura 11. Formas de abastecimiento de agua por municipio

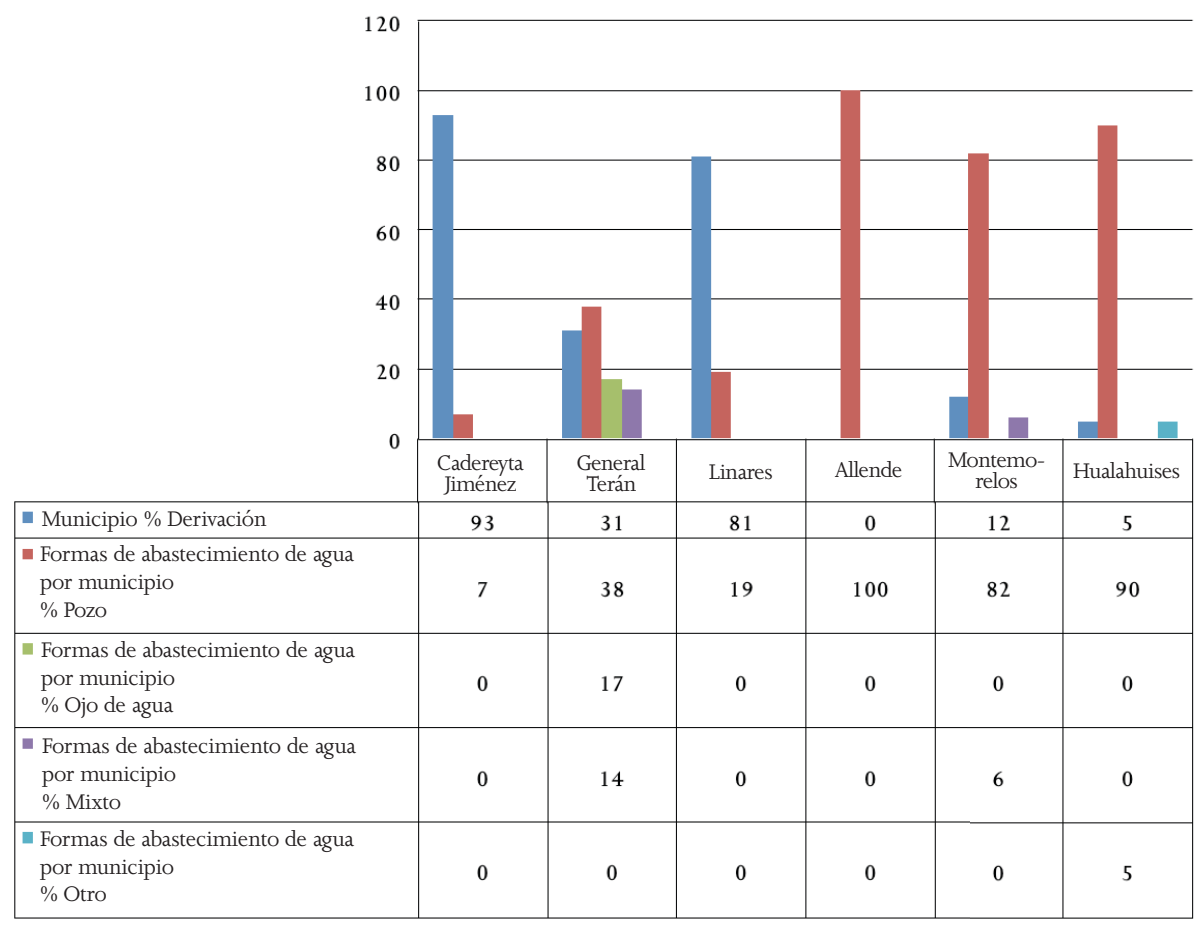

Fuente: elaboración propia, con datos del trabajo de campo.

Después se detallan las relaciones comerciales entre los productores y los consumidores, con base en el tipo de tenencia de la tierra, los sistemas de riego imperantes y las formas de abastecimiento de agua. En los seis municipios aparece la figura del intermediario como el primer contacto para comercializar el producto. Los datos señalan que en Montemorelos dicho actor está presente en todos los informantes entrevistados, le sigue Cadereyta Jiménez, donde poco más de 96 por ciento afirma que incide drásticamente en la parte comercial, en la variable precios. En Hualahuises, más de 90 por ciento sostiene lo mismo en cuanto a la presencia de intermediarios, le sigue Linares, Allende y General Terán, con 86, 82 y 80 por ciento. 
Figura 12. Relaciones comerciales citrícolas por municipio

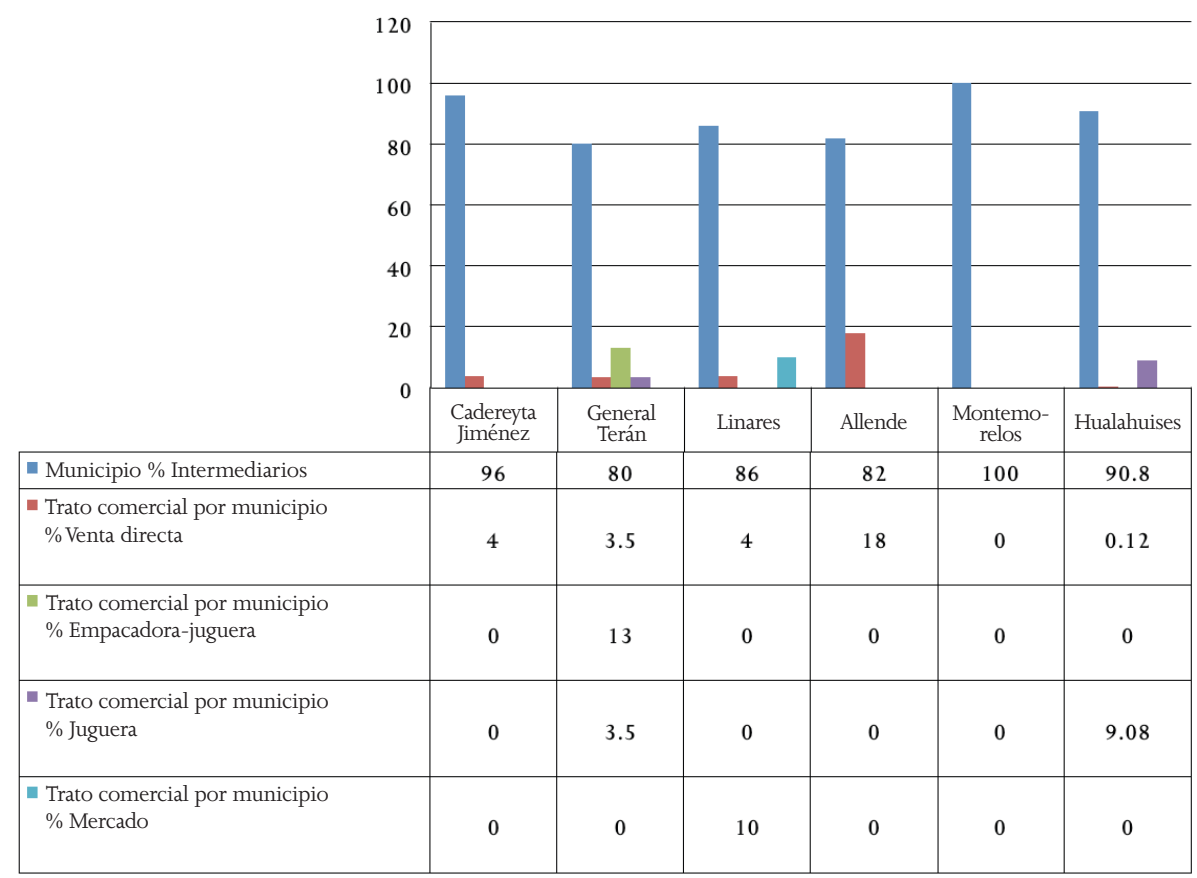

Fuente: elaboración propia, con datos del trabajo de campo.

En Cadereyta Jiménez y Allende la comercialización de venta directa es la segunda opción, en General Terán el trato directo con la empacadora y juguera es una forma secundaria de relación económica. En Linares, la relación directa con los mercados aparece como tercera opción, y en Hualahuises lo hacen de forma secundaria con la juguera.

\section{Análisis de la comercialización de la citricultura de Nuevo León}

Los distribuidores de cítricos tienen relación directa con el sector agroindustrial, al estar cerca de los empacadores, proveedores y todos 
los agentes involucrados en la actividad. Ellos tienen recursos propios y medios para trasportar el producto de Montemorelos, Allende, Linares, Hualahuises y General Terán. Después lo comercializan en tiendas, supermercados, tianguis y fruterías, entre otros lugares. Los compradores cubren los costos de trasporte y maniobras de traslado, aunque hay ocasiones en que el productor, el proveedor o el intermediario costean el traslado. Es importante señalar que el productor proveedor o intermediario traslada la mercancía hacia el lugar de abasto para su venta y descarga, costo que por lo regular sufraga el distribuidor. El productor comercial de cítricos mantiene una dinámica local importante, pues el primer destino más grande es la central de abastos, que es el enlace con mercados, tianguis, tiendas, supermercados y restaurantes.

Los distribuidores tienen una relación directa con los productores, los proveedores y los intermediarios, acción que garantiza el abasto del producto, su presentación, calidad, valor y precio. Las encuestas realizadas en el mercado de abastos Estrella de San Nicolás de los Garza, Nuevo León, arrojaron que las bodegas o comercios distribuidores tienen entre 10 y 45 años (véase Figura 13). Existe una especialización en el manejo de la naranja, la toronja, la mandarina y el limón, la mayor parte de estos frutos se cosechan en la zona citrícola de Nuevo León, excepto el limón, que procede de Colima, Veracruz y Michoacán. Gran parte de los responsables de las compras son los dueños de las distribuidoras.

Figura 13. Antigüedad de los establecimientos

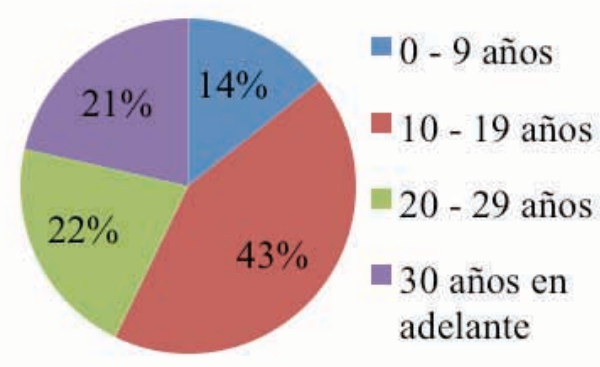

Fuente: elaboración propia, con datos del trabajo de campo. 
La antigüedad de 43 por ciento de las distribuidoras es de 10 a 19 años; 22 entre 20 y 29; 21 tiene 30 o más años y 14, de 0 a 9. Lo anterior permite considerar la amplia experiencia que se tiene en la compraventa de frutos; el limón, la naranja, la toronja, la mandarina y la piña son los que más se comercializan (véase Figura 14). En la Figura 15 se muestra la procedencia de los cítricos cuya clasificación la realiza 86 por ciento de los productores, y 14 no le da importancia. En la Figura 16 aparece el porcentaje de la calidad de los productos; la garantía del abasto de éstos se muestra en la Figura 17, y en la Figura 18 aparece el porcentaje de las relaciones comerciales para adquirir los cítricos, que están condicionadas por el tamaño y su color.

Figura 14. Tipo de cítricos comercializables en la central de abastos

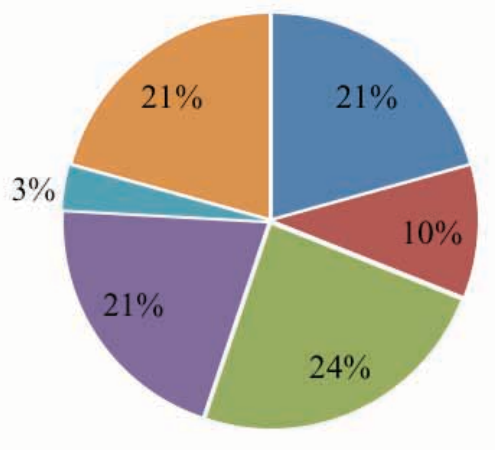

- Limón con semilla

- Limón sin semilla

"Naranja

- Toronja

" Piña

$\square$ Mandarina

Fuente: elaboración propia, con datos del trabajo de campo.

Figura 15. Procedencia de productos cítricos

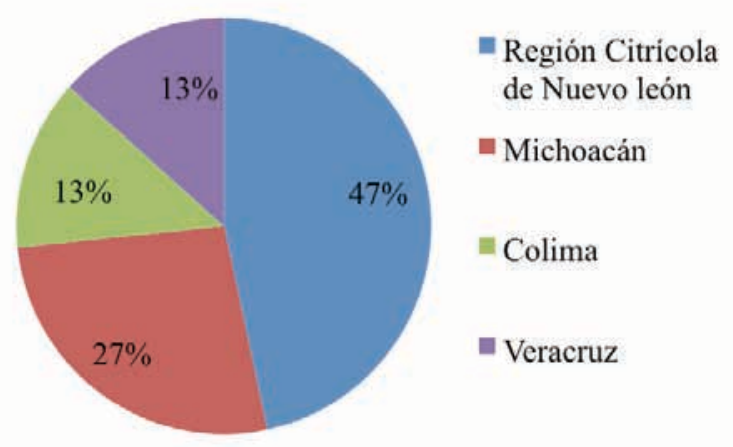

Fuente: elaboración propia, con datos del trabajo de campo. 
Figura 16. Calidad de productos del centro de abastos

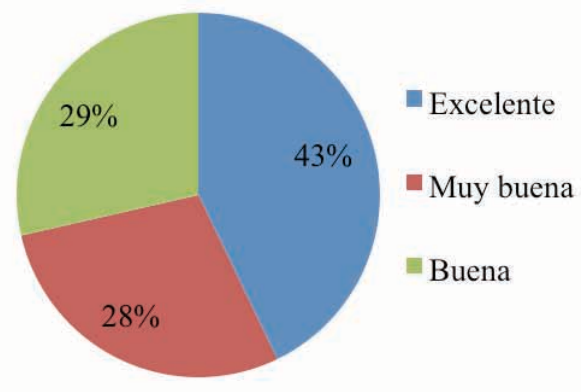

Fuente: elaboración propia, con datos del trabajo de campo.

Figura 17. Garantía de productos cítricos en la central de abastos

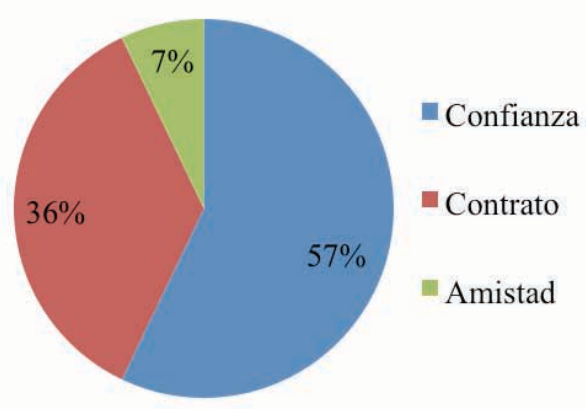

Fuente: elaboración propia, con datos del trabajo de campo.

Figura 18. Clasificación de los cítricos que se comercializan en la central de abastos

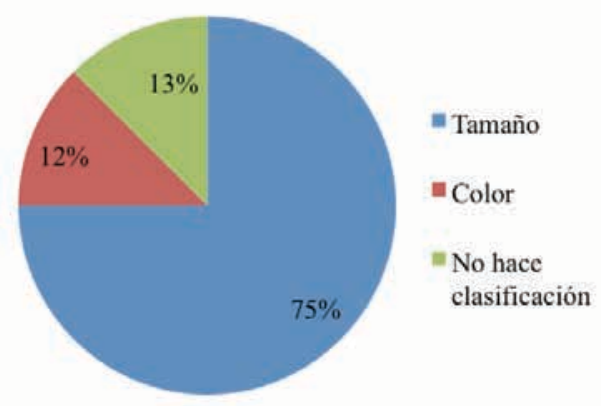

Fuente: elaboración propia, con datos del trabajo de campo. 
Los elementos anteriores condicionan la calidad, además de ser fundamentales para hacer conciencia cultural sobre el producto típico de una región. En el caso de la importancia de la utilidad de la marca registrada, sólo 36 por ciento comercializa cítricos con una, mientras que 64 no considera importante este aspecto. El porcentaje de los actores que surten cítricos a las distribuidoras se describe en la Figura 19.

Figura 19. Tipo de proveedor de cítricos

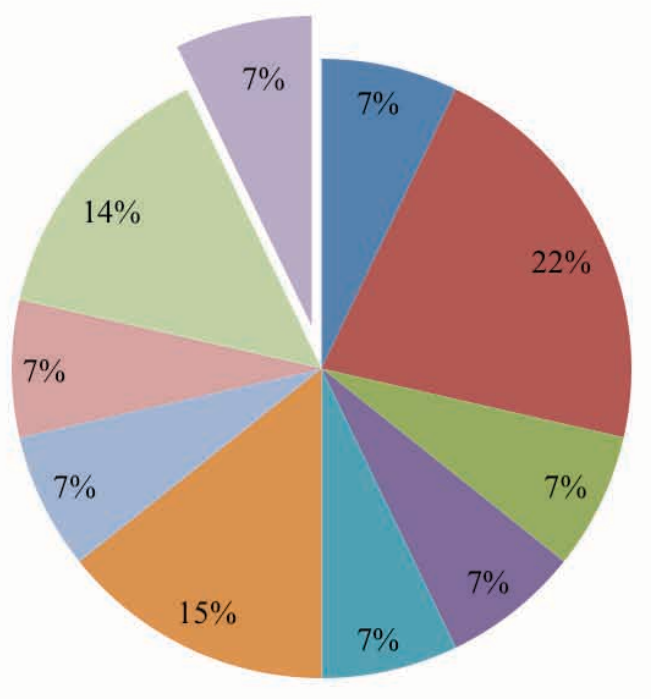

- Productor en asociación

- Productor proveedor

- Productor empacador

Productor empacador intermediario

- Proveedor intermediario

Productor

Productor proveedor intermediario

Productor empacador proveedor

Proveedor empacador

= Intermediario

Fuente: elaboración propia, con datos del trabajo de campo.

El plazo de pago de los distribuidores se especifica en la Figura 20; sólo 21 por ciento de los distribuidores financian a los proveedores a cuenta del producto. En la Figura 21 se aprecia que 79 por ciento de los compradores costean el trasporte que distribuye los productos. 
Figura 20. Plazo de pago a los comerciantes de cítricos de la central de abastos

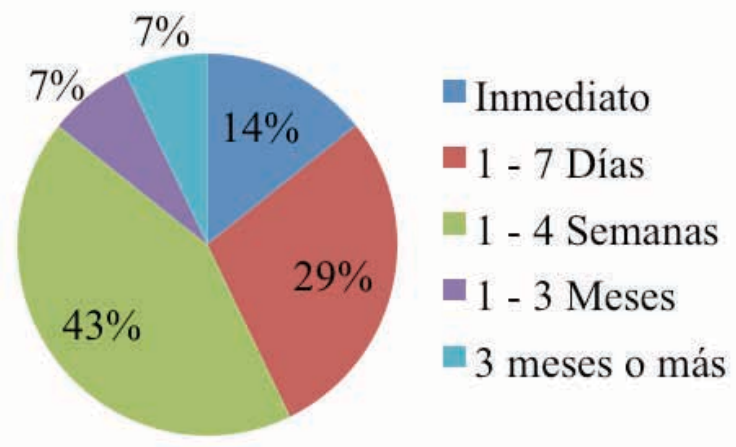

Fuente: elaboración propia, con datos del trabajo de campo.

Figura 21. Trasportación de los cítricos de Nuevo León a la central de abastos

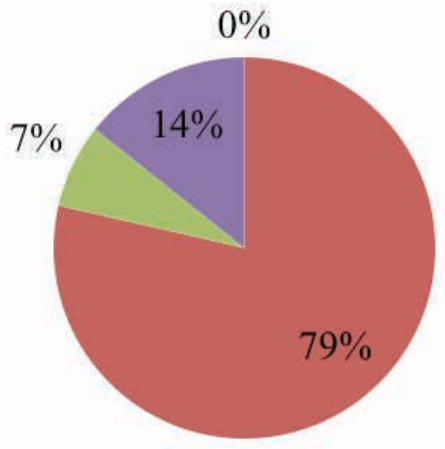

Pago de Transporte

- Comprador

Productor Proveedor

- Proveedor

Fuente: elaboración propia, con datos del trabajo de campo.

En la Figura 22 aparece el actor que fija los precios de los cítricos, y en la 23 el porcentaje en cuanto a la capacidad de almacenamiento en toneladas por semana de los comerciantes. La distribución de las mermas por semana aparece en la Figura 24, y en la 25 se muestra el porcentaje de los clientes de los cítricos. 
Figura 22. Actor responsable de fijar precios de los cítricos

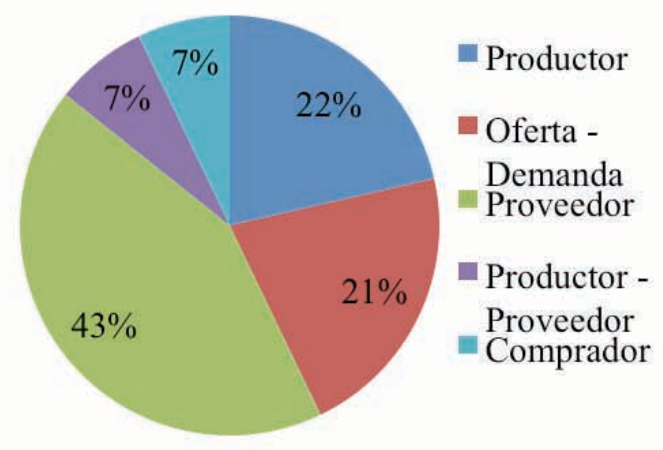

Fuente: elaboración propia, con datos del trabajo de campo.

Figura 23. Capacidad de almacenamiento en la central de abastos

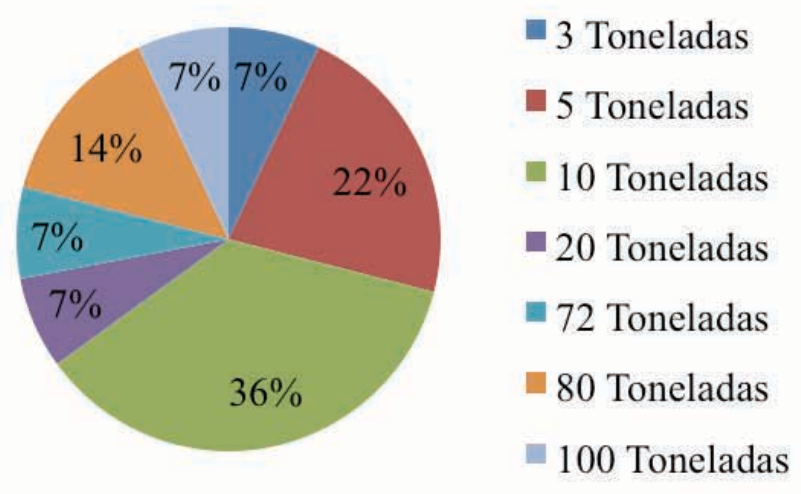

Fuente: elaboración propia, con datos del trabajo de campo. 
Figura 24. Estimación de mermas de los cítricos en la central de abastos

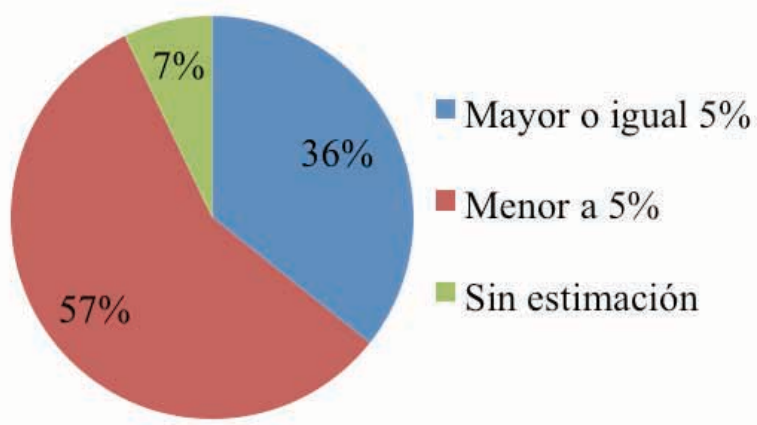

Fuente: elaboración propia, con datos del trabajo de campo.

Figura 25. Compradores de cítricos en la central de abastos

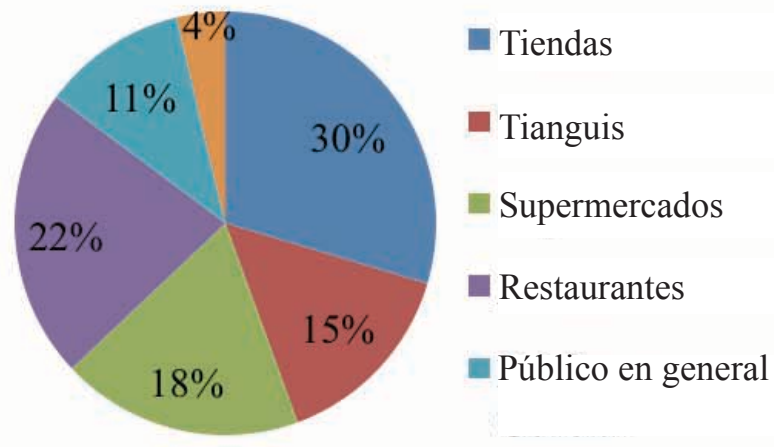

Fuente: elaboración propia, con datos del trabajo de campo.

Sólo 86 por ciento otorga crédito a sus clientes, y 14 no lo hace por desconfianza. El crédito se ofrece en plazos de una a tres semanas y un mes o más (véase Figura 26). En la Figura 27 se especifica el porcentaje en la forma de pago de los clientes. En cuanto a la presentación del producto, la ilustración aparece en la Figura 28, y en la 29 se muestra la tendencia en la venta de cítricos de 2014 a 2016. 
Figura 26. Clientes que solicitan crédito en la central de abastos

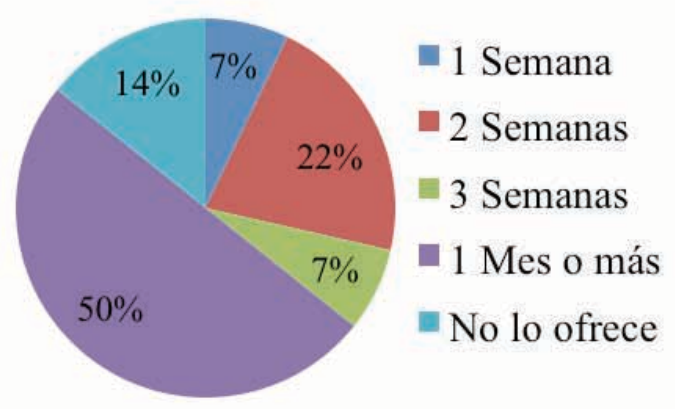

Fuente: elaboración propia, con datos del trabajo de campo.

Figura 27. Pago para la adquisición de productos en la central de abastos

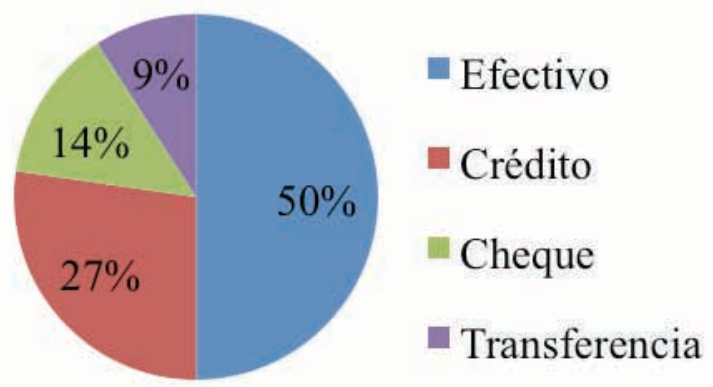

Fuente: elaboración propia, con datos del trabajo de campo.

Figura 28. Presentación de los cítricos comercializables en la central de abastos

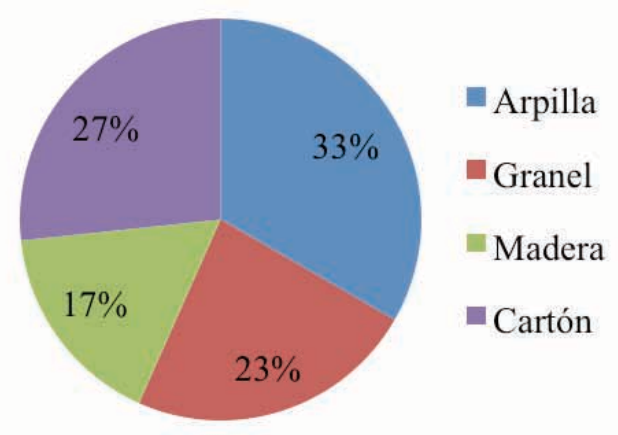

Fuente: elaboración propia, con datos del trabajo de campo. 
Figura 29. Tendencia de ventas de los cítricos comercializables en la central de abastos de 2014 a 2016

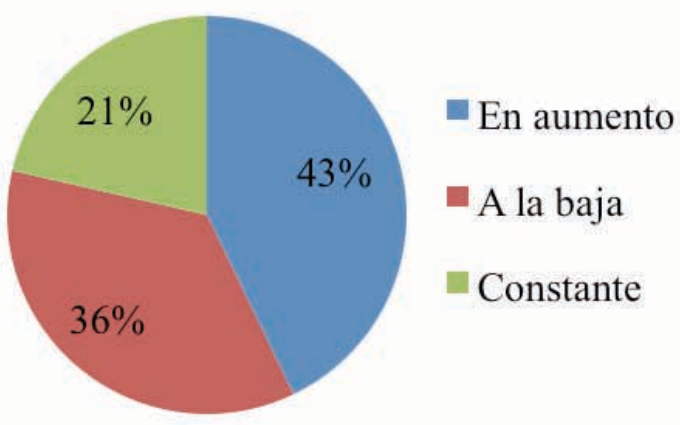

Fuente: elaboración propia, con datos del trabajo de campo.

\section{Relaciones entre productor y agroindustria}

La dinámica de los procesos de la producción y la comercialización agrícolas quedó plasmada en el trabajo de campo, para lo que se realizaron entrevistas y encuestas. En ambos procesos se analizaron más de cien productores y se generaron datos cuantitativos; se obtuvieron las características de la colocación del producto en 14 puntos comerciales. En el análisis de Gaitán menciona que, en teoría, ha habido alianzas temporales y esporádicas entre productores y empacadores, sobre todo para atender oportunidades comerciales coyunturales no planeadas. Por ejemplo, que "México improvisó el desarrollo de su industria citrícola, ya que la oferta es principalmente afectada por efectos del clima, y que existen barreras fitosanitarias que hacen imposible exportar fruta, y por lo tanto, era urgente que el gobierno mexicano acelerara las negociaciones con EUA para lograr la aceptación de nuevas medidas fitosanitarias que favorecieran a los productores mexicanos" (Hernández 2015, 53), lo cual dio continuidad a esta forma de operar y tratar el negocio. 
La demostración es sólo de asociacionismo lineal de productores, empacadores, procesadores y comerciantes, cuyo objetivo en una primera aproximación fue la comercialización de la naranja en pequeños grupos, para venderla a otros productores (Gaitán 2002, 120-126). Aunado a lo anterior está el intermediario, un elemento más que surgió de manera irregular, en el asociacionismo lineal, y que para los productores representa el empleo de información del mercado, las conexiones con centros de abasto, el manejo de trasporte, los costos y los egresos.

Existen dos formas de comercialización: a) los grupos pequeños de asociados que venden la mercancía y la adquieren también de otros, los cuales, según el trabajo de campo, se podrían denominar productores proveedores y b) una empacadora que envía la fruta al mercado a través de un intermediario, que la logra introducir con conexiones y canales de comercialización (Gaitán 2002, 120-126). La vía de introducción al mercado estadounidense se realiza por medio de brokers, ${ }^{3}$ mientras que hay algunos que no logran entrar debido a los altos costos de producción, a diferencia de lo que sucede en otros países. En la región, las principales agrupaciones de asociación, empacadoras y procesadoras forman tres bloques: las organizaciones citrícolas, como la Unión Estatal de Citricultores, el Consejo Estatal Agrícola y las asociaciones agrícolas locales. Después, las empacadoras de cítricos de Nuevo León, las cuales exportan a Estados Unidos, Argentina, Canadá, Francia y Uganda. Por último, las plantas procesadoras de cítricos donde se procesa jugo simple natural y pasteurizado de naranja y mandarina, además de aceite esencial de naranja, que se exporta a Canadá y Estados Unidos; también comercializan gajos de naranja y toronja refrigerados y congelados (OEIDRUS 20 I 2a; Mexbest Safety and Quality Taste s/f).

Sánchez (1990), en su trabajo detalla la existencia de empresas dedicadas a la agroindustria, también se expone el número de trabajadores y el mercado al cual abastecen. Este sistema de productividad inicia con la producción del fruto, y luego pasa a la agroindustria para su trasformación. Es decir, la comercialización tiene dos direcciones,

3 Agentes intermediarios en operaciones comerciales agrícolas, que perciben una comisión al intervenir en dicho proceso. 
la comercial y la juguera o agroindustrial. Las empacadoras le añaden el valor agregado de lavado, cepillado, pintado y encerado al producto; el proceso agroindustrial conlleva la selección por tamaño y aspecto, y la separación se realiza a través de maquinaria especializada. El sistema agroindustrial empieza con la selección del fruto, luego se trasporta y almacena en bodegas, de ahí se pasa a las empacadoras donde comienza el lavado, pintado, cepillado, encerado y la separación. Después se envía a supermercados y centrales regionales y nacionales, y también a los de Estados Unidos, Japón y Canadá (OEIDRUS 2012a, 20), pero con su valor agregado.

Industrias Citrícolas de Montemorelos, una de las empresas principales y de las más importantes, empaca cítricos para ensaladas; de 90 a 95 por ciento de su mercado es Estados Unidos, Canadá, Japón, Corea y Taiwán; pero también atiende la demanda de naciones en una escala de 5 a 10 por ciento. Tiene 42 años de experiencia en el ramo citrícola, cuenta con más de 300 técnicos y supera los 1600 trabajadores de apoyo en procesos de selección, corte, envasado, venta y distribución de frutas en presentaciones distintas. Su éxito se basa en el desarrollo de productos y mercados nuevos, y en la generación de empleos y de desarrollo profesional, técnico y de alta tecnología e innovación con enfoque sustentable. Según datos obtenidos del trabajo de campo, la empresa tiene relación comercial con más de mil productores en todo México, y en Nuevo León mantiene más de 150, que pertenecen a varias asociaciones y, en conjunto, cumplen los requisitos sanitarios y de utilización sustentable de fertilizantes; así se asegura el asociacionismo con el sector agroindustrial.

\section{Conclusiones}

La introducción del ferrocarril a Nuevo León, junto con la visión de su administrador, quien se percató de las características de la región en cuanto a recursos naturales, fueron los catalizadores para la configuración de la zona citrícola, que más tarde enfrentó la demanda interna y externa, traducida en alineaciones comerciales nacionales e internacionales. En Nuevo León fueron surgiendo productores citrícolas que se dedicaron a surtir a empresas para la poscosecha, la co- 
mercialización y la exportación. Conforme la producción de cítricos se elevaba, las empresas se fueron agrupando de manera territorial y conformaron organizaciones caracterizadas por acuerdos comerciales intermitentes y esporádicos, según las oportunidades de comercio que se presentasen. En los estudios realizados quedó claro que el problema es la falta de integración entre actores y su incorporación formal, pero no en el aspecto operativo, el cual es el más importante. La pertinencia de las cualidades del área quedaron integradas en el sistema producto, que se caracterizó y definió como el conjunto de elementos y agentes concurrentes de los procesos productivos de bienes agropecuarios, incluidos el abastecimiento de equipo técnico, los insumos y servicios de la producción primaria, el acopio, la trasformación, la distribución y la comercialización (SAGARPA 2012). En el mismo sistema se proporcionaron estrategias para la integración sectorial y empresarial. El enfoque de los sistemas agroalimentarios localizados posee una visión dinámica, esto se debe a que los recursos son trasformados en productos que configuran relaciones e interacciones entre actores, que a su vez los controlan e integran a actividades económicas (Instituto Interamericano de Cooperación para la Agricultura 2013). Por lo cual es pertinente aplicar el enfoque de los SIAL en la zona citrícola de Nuevo León.

La mejor forma de lograr la integración es en virtud de las similitudes y diferencias de cada actor o parte involucrada, esto produce análisis estratégicos, entendidos como piezas clave para diagnosticar el modo de prevalecer de un sector, y a partir de ellos conocer la situación en que se encuentra, y generar mecanismos y estrategias para progresar y desarrollar sus actividades de mejor manera. También se obtuvo información concluyente, de forma cualitativa, mediante una matriz de dos aspas analíticas presentadas a los 156 productores informantes de los municipios señalados, donde se detectaron las necesidades o se identificaron los problemas y las ventajas estratégicas. Cada una está conformada por dos cúmulos, uno formado por dos áreas que aluden a las fortalezas y las oportunidades, consistente en las ventajas y las condiciones favorables del sector; la primera constituida por las fortalezas que hacen exitosa y operativa cierta actividad, y la segunda son las oportunidades, que a su vez se identifican como las áreas de oportunidad que pueden ser las visiones o las lagunas que se tienden a llenar con proyectos distintos. El segundo cúmulo 
es la identificación de problemas, o detección de necesidades, que se refiere a las características y los aspectos internos de la actividad económica y comercial, y el entorno imperante en ella.

El sector citrícola, desde los productores hasta la agroindustria, se encuentra en un estado activo progresista, debido a sus fortalezas, que se traducen en la importancia de las características edafológicas y de benevolencia de la región, la cual genera variedades de cítricos por sus insumos de semillas, y sistemas amplios de riego, los productos obtenidos se comercializan en México y en el extranjero en lugares de mercadeo fluido y amplio como dinámica territorial económica porque existen agroindustrias cercanas, las cuales generan trasformación y mayor oferta de empleo en los ramos de producción, empaque, procesamiento y comercialización. Este proceso le brinda un gran reconocimiento a los productos de la región, y coadyuva al fortalecimiento de cambios culturales cuya tradición configura la feria de los cítricos.

Lo anterior establece, como ámbito de oportunidades, la existencia de un futuro promisorio con la introducción de cítricos sin semilla como plataforma de innovación tecnológica vanguardista, resultado de convenios empresariales que buscan apoyo gubernamental para la mecanización, como el uso de tractores para deshierbar. Asimismo, activa la apertura para proyectos de investigación científica con vinculación hacia espacios universitarios profesionales y técnicos, que producirán crecimiento económico y social fraguado por la citricultura y el turismo. El sector enfrenta inviernos crudos y sequías que repercuten en el rendimiento, no hay control de plagas y enfermedades, falta asistencia técnica y capacitación contra la mosca de la fruta y la inversión es nula, debido a la desconfianza provocada por las adversidades. Además, la preocupación por la injerencia constante de intermediarios y falta de unidad empresarial, la inestabilidad del capital humano por la migración, la inseguridad, los costos de la energía, el trasporte y los fertilizantes.

Lo gratificante de las matrices obtenidas de los informantes clave es la información común, que es un eslabón de asociacionismo al conformarse acuerdos sobre alternativas ante las problemáticas, entre las cuales destacan el manejo de información climática, surgida de instituciones nacionales e internacionales, la nutrición y árboles sanos, las 
podas adecuadas, el manejo de plagas y el humedecimiento de suelos secos. Es importante utilizar tarjetas especificadoras de control de sanidad y calidad, trasformar a los intermediarios en gestores sistémicos validados por productores y empresas o agroindustrias, impartir cursos de capacitación y adiestramiento anuales o semestrales con actualizaciones técnicas, así como la capacitación y adiestramiento del capital humano permanente, que fomenta las prestaciones y salarios adecuados; también la creación de programas de desarrollo regional, como educación técnica de calidad en cada región productiva, para generar el capital humano adecuado para las actividades laborales inherentes al sitio. Los costos se pueden financiar en la medida en que se generan las sinergias y la unidad entre actores de un verdadero sistema producto. Si se incluye la educación técnica para detonar a una región, las pautas generacionales se irán modificando y surgirá la culturización y la confianza en las actividades comerciales, aumentará el sector laboral y habrá mayores y mejores programas de gobierno donde se incruste la importancia de la seguridad para el crecimiento económico.

\section{Bibliografía}

Bericat, E. 1999. La integración de los métodos cuantitativo y cualitativo en la investigación social. Barcelona: Ariel.

Bernal, C. A. 2006. Metodología de la investigación. México: Pearson Educación de México.

Boucher, F. A. 2012. Sistemas Agroalimentarios Localizados en América Latina. Alternativas para el desarrollo territorial. México: Porrúa.

Bueno, E. 2003. Latin American Studies Association. http://lasa.international.pitt.edu/Lasa2003/BuenoSanchezEramis.pdf (2014).

Caldentey, A. 1998. El distrito agro-comercial del campo de Dalías (España). Agroalimentaria IV (7): 21-28. 
Cano, E. 2013. Mexican business web. www.mexicanbusinessweb. $\mathrm{mx} /$ sectores-productivos-de-mexico/agropecuario/mexicoquinto-productor-de-citricos-en-el-mundo/ (28 de enero de 2014).

Centro de Estudios Estratégicos del Instituto Tecnológico y de Estudios Superiores de Monterrey (ITESM). 2001. Integración y desarrollo de cluster de naranja en fresco del estado de Nuevo León. Monterrey, Nuevo León, México. MSDA: www.amsda.como.mx/PREstatales/ Estatales/NUEVOLEON/PRE citricis.pdf (24 de agosto de 2014).

CEPAL-FAO-Gesellschaft für Technische Zusammenarbeit. 1998. Ruralfinance. http://www.ruralfinance.org/fileadmin/templates/ rflc/documents/1176915174209_Agroindustria_A.Latina.pdf (2015).

Comisión Económica para América Latina y el Caribe-Food and Agriculture Organization (CEPAL-FAO). 1998. Rural finance. http://www.ruralfinance.org/fileadmin/rflc/documents/117691517420 9_Agroindustria_A.Latina.pdf (10 de septiembre de 2015).

Comité Estatal de Información Estadística y Geografía para el Desarrollo Rural Sustentable del Estado de Nuevo León. 2012. Estudios $e$ investigaciones. http://www.agronuevoleon.gob.mx/oeidrus/ESTUDIOSE INVESTIGACIONES/AGRICULTURA/CITRICULTURA /2introduccion.pdf

Comité Estatal de Información Estadística y Geografía para el Desarrollo Rural Sustentable del Estado de Nuevo León. 2002. Estudios e investigaciones. HTTP://WWW.AGRONUEVOLEON.GOB.MX/ OEIDRUS/ESTUDIOSE INVESTIGACIONES/AGRICULTURA/ CITRICULTURA/2introduccion.pdf

Consejo Citrícola Mexicano, A. c. 2009. Estudio orientado a identificar las necesidades de infraestructura logística en la cadena de suministro de cítricos para la exportación de jugo a los mercados meta identificados. México: SAGARPA. 
Consejo Estatal Citrícola Veracruz, A. C. 2012. Plan Rector del Sistema Producto Cítricos Veracruz. Veracruz.

Diario Oficial de la Federación. 2001/2012. Ley de Desarrollo Rural Sustentable. 12 de enero de 2012.

FAO. 2003. Tenencia de la tierra y desarrollo rural. No. 3. Roma: FAO.

FIRA. 2016. Apoyos a producción. https://www.fira.gob.mx/Nd/index.jsp (octubre de 2016).

Fujigaki, E. 2000. La agricultura, siglos XVI al XX. En Historia económica de México, coordinado por E. Semo. México: Fomento Editorial Universidad Nacional Autónoma de México (UNAM) y Océano de México.

Gaitán, J. 2002. Situación de la citricultura del estado de Nuevo León. Monterrey: ITESM.

García, G. J. 2009. El origen de la citricultura moderna en México. En El cultivo de cítricos en el estado de Nuevo León, editado por M. Rocha Peña y J. Padrón, 3-26. México: Instituto Nacional de Investigaciones Forestales, Agrícolas y Pecuarias.

Garza, I. C. 1998. Breve historia de Nuevo León. México: El Colegio de México - Fondo de Cultura Económica.

Gobierno del Estado de Nuevo León. 2010. Alianza para el futuro 2020 del estado de Nuevo León. http://beta.nl.gob.mx/sites/default/files/Pacto_Ambiental_0.pdf (14 de noviembre de 2014).

González, L. 1988. El oficio de historiar. México: El Colegio de Michoacán.

Grass, F. 2012. El enfoque de los sistemas agroalimentarios localizados-SIAL:propuestas para el fortalecimiento metodológico. Texcoco de Mora: Centro de Investigaciones Económicas Sociales y Tecnológicas de la Agroindustria y la Agricultura Mundial, Universidad Autónoma Chapingo. 
Gutelman, M. 2000. ¿Qué es el ejido? En La agricultura. Siglos XVI al XX, de E. Fujigaki, 165-168. México: Fomento Editorial de la UNAM y Océano de México.

H. Congreso del Estado de Nuevo León. 2010a. Ley Ambiental del Estado de Nuevo León. www.inegi.org.mx/est/contenidos/proyectos/aspectosmetodologicos/clasificadoresycatalogos/doc/estatal/ LadedNuevoLeon.pdf (14 de noviembre de 2014).

H. Congreso del Estado de Nuevo León. 2010b. Ley de Desarrollo Rural Integral Sustentable del Estado de Nuevo León. http://www. hcnl.gob.mx/trabajo_legislativo/leyes/leyes/ley_de_desarrollo_ rural_integral_sustentable_del_estado_de_nuevo_leon/ (14 de noviembre de 2014).

Hernández, M. 2015. Análisis competitivo de sistemas de producción de naranja (Citrus sinensis) en Nuevo León, México. Agroproductividad: 52-59.

Hernández, R. 2010. Metodología de la investigación. México: McGraw Hill.

Instituto Nacional de Estadística y Geografía (INEGI). 2014. Boletín de información oportuna del sector alimentario. http://www. inegi.org.mx/prod_serv/contenidos/espanol/bvinegi/productos/integracion/sectorial/biosa/biosa.pdf (14 de noviembre de 2014).

INEGI. 2010a. Población. http://cuentame.inegi.org.mx/monografias $/$ informacion $/ \mathrm{nl} /$ poblacion $/$ default.aspx?tema $=$ me\&e $=19$

INEGI. 2010b. Población. www.inegi/poblacion.rtd.pdf

INEGI. 2008. Estadísticas históricas de los municipios de Nuevo León. 2008. Censo de población y vivienda. Estadísticas históricas de los municipios de Nuevo León, tomo II. México: INEGI.

INEGI. 1994. Estadísticas históricas de México, tomo I. México: INEGI. 
Instituto de Competitividad Sistémica y Desarrollo. 2005. Programa de competitividad y modelo de negocio en la cadena global de valor del sector frutícola de Nuevo León: cítricos y nuez. Monterrey: Fundación Produce N. L., A. C. / Corporación para el Desarrollo Agropecuario de Nuevo León.

IICA. 2013. Sistemas agroalimentarios localizados (SIAL), una nueva visión de gestión territorial en América Latina: experiencias en territorios de Argentina, Costa Rica, Ecuador y México. México: IICA, CIRAD.

Krugman, P. 1995. Repositorio institutcional: Sistema Nacional de Bibliotecas-Vicerrectoría de Investigación, Colombia. http://www. bdigital.unal.edu.co/26177/1/23735-82979-1-PB.pdf (20 de noviembre de 2016).

León, A. D. 1980. Relación y discursos del descubrimiento, población y pacificación de este Nuevo Reyno de León, temperamente y calidad de la tierra hechos por el capitán Alonso de León. Monterrey: Ayuntamiento de Monterrey.

Luna, A. M. 2014. Historia ambiental. En Región citrícola de Nuevo León. Su complejidad territorial en el marco global, coordinado por A. López López y M. Pando, 29-42. México: UNAM.

Martínez, M. 1997. La investigación cualitativa etnográfica en educación. Manual teórico práctico. Bogotá: Círculo de Lectura Alternativa.

Martínez, P. 2006. El método de estudio de caso. Estrategia metodológica de la investigación científica. Pensamiento y Gestión (20): 165193. http://www.redalyc.org/articulo.oa?id=64602005>

Mata, J. J. 2011 . Articulación productiva para la innovación en las pequeñas empresas acuícolas de la región occidente de México. El Ágora: 403-422.

Mazoyer, M. 2001. Defendiendo al campesinado en un contexto de globalización. Roma: FAO. 
Merla Rodríguez, G. 1990. Nuevo León. Geografía regional. General Zuazua: Centro de Información de Historia Regional, UANL.

Mexbest Safety and Quality Taste. s/f. http://http://www.mexbest. com (23 de agosto de 2014)

Muchnik, J. D. 1998. Proposition d action thématique programmée:systémes agralimentaires localisés et construction de territories. Francia: CIRAD.

Murillo, M. B. 2012. El agroturismo como instrumento de activación de los SIAL en América Latina: valoración del potencial turístico en 10 casos de estudio. En Sistemas agroalimentarios localizados en América Latina. Alternativas para el desarrollo territorial, editado por F. A. Boucher, A. Espinoza y M. Pensado, 121-138. México: Porrúa.

OEIDRUS. 20 i 3 . OEIDRUS Nuevo León. http:/ /www.agronuevoleon. gob.mx (9 de octubre de 2013).

OEIDRUS. 2012a. Agronuevoleón. www.agronuevoleon.gob.mx

OEIDRUS. 2012b. Estudios de estratificación de productores de Nuevo León. http://www.agronuevoleon.gob.mx/oeidrus/ ESTUDIOS_E_INVESTIGACIONES/ESTATALES/estratificaciongym.pdf

OEIDRUS. 2012c. Plan Rector del Sistema Producto de Cítricos de Nuevo León. Monterrey, Nuevo León.

OEIDRUS. 2012d. OEIDRUS Nuevo León. http://http://www.agronuevoleon.gob.mx/ (23 de agosto de 2014).

OEIDRUS Nuevo León. 2011. Oficina estatal de información para el desarrollo rural sustentable. www.agronuevoleon.gob.mx

OEIDRUS. s/f. OEIDRUS Nuevo León. http://http://www.agronuevoleon.gob.mx/ (23 de agosto de 2014). 
Olvera Sandoval, J. A. 2009. Montemorelos: reino de piloncillo y de naranjos. En Nuevo León a través de sus municipios, tomo III, coordinado por C. Morado, 258-284. Monterrey: Grupo Milenio.

Olvera Sandoval, J. A. 1991. El valle del Pilón: riego, producción e impactos socioeconómicos (1880-1910). En Agua, tierra y capital en el noreste de México, coordinado por M. Cerutti, 146-150. Monterrey: Facultad de Filosofía y Letras (FFYL) de la UANL.

Olvera, J. A. 1987. La citricultura en Montemorelos. Sus inicios (1890-1910). El noreste. Siete estudios históricos, coordinado por M. Cerutti. Monterrey: FFYL de la UANL.

Ortega, I. 2005. Génesis y evolución de la administración pública en Nuevo León. Monterrey: Fondo Editorial Nuevo León.

Poméon, T. 2011 . SIAL: un enfoque para el desarrollo territorial. Cuaderno de trabajo No. 5. México: IICA, CIRAD.

Sachs, W. 2002. Globalización y sustentabilidad. Uruguay. www.worldsummit2002.org

Sachs, W. 1996. Desarrollo. En Diccionario del desarrollo, editado por G. Esteba. Perú: PRATEC.

SAGARPA. 2012. México, entre los líderes en producción de cítricos a nivel mundial. San Luis Potosí: SAGARPA.

Sánchez, V. 1990. Evolución económica de la región citrícola de Nuevo León: 1960-1990. En La región citrícola de Nuevo León. Actores, condiciones y perspectivas, coordinado por V. Zúñiga, 9-38. México: FFYL de la UANL y El Colegio de la Frontera Norte (COLEF).

Secretaría de Desarrollo Agropecuario, Pesca y Acuacultura. 20102016. Sistema Producto Cítricos Oaxaca. Oaxaca: Secretaría de Desarrollo Agropecuario, Pesca y Acuacultura. 
SIAP. 2013. Anuario de producción agrícola. http://infosiap.siap.gob. $\mathrm{mx} /$ aagricola_siap_gb/icultivo/

SIAP-SAGARPA. 2012. Servicio de Información Agroalimentaria y Pesquera. www.sagarpa.gob.mx

SIAP-SAGARPA. 2011. Sistema de Información Agroalimentaria y Pesquera. www.sagarpa.gob.mx

Sieglin, V. 1995. La disputa por el agua en el noreste de México (1820-1970). Ciudad Universitaria, San Nicolás de los Garza: Claves Latinoamericanas S. A. de C.V. / FFYL de la UANL.

Sieglin, V. 1994. Ejidos: entre la acumulación y descapitalización. El centro-sur de Nuevo León (1950-1970). En Producción, ejidos y agua en el noreste de México. La región citrícola de Nuevo León (siglos XIX y XX), compilado por M. Cerutti, 15-16. Monterrey: FFYL de la UANL.

Sieglin, V. 1990. Antecedentes económicos de la región: tenencia de la tierra y distribución del agua. En La región citrícola de Nuevo León, coordinado por V. Zúñiga. Monterrey: FFYL de la UANL / COLEF.

Sieglin, V. 1987. La formación de la burguesía citrícola en Nuevo León (1920-1935). En Monterrey, Nuevo León, el noreste. Siete estudios históricos, coordinado por M. Cerutti, 215-239. Monterrey: FFYL de la UANL.

Vázquez, L. 1990. La región citrícola de Nuevo León ante la citricultura mundial. En La región citrícola de Nuevo León. Actores, condiciones y perspectivas, coordinado por V. Zúñiga, 173-196. Monterrey: FFYL de la UANL / COLEF.

Vázquez, J. A. y M. A. González. 1987. Capitalistas norteamericanos en Monterrey: Joseph A. Robertson. En Monterrey, Nuevo León. Siete estudios históricos, coordinado por M. Cerutti, 177-214. México: FFYL de la UANL. 
Velarde, I. 2012. Activación de sistemas agroalimentarios en la región pampeana argentina: un análisis comparado. En Sistemas agroalimentarios localizados. Identidad territorial, construcción de capital social e instituciones, coordinado por Gerardo Torres Salcido y Rosa María Larroa Torres, 135-159. México: UNAM. 